\title{
Manufacturing and Corporate Environmental Responsibility: Cost Implications of Voluntary Waste Minimisation
}

Wendy Chapple, Catherine J. Morrison Paul \& Richard Harris

\author{
Research Paper Series \\ International Centre for Corporate Social Responsibility \\ ISSN 1479-5124 \\ Editor: Dirk Matten \\ International Centre for Corporate Social Responsibility \\ Nottingham University Business School \\ Nottingham University \\ Jubilee Campus \\ Wollaton Road \\ Nottingham NG8 1BB \\ United Kingdom \\ Phone +44(0)1159515261 \\ Fax +44 (0)1158466667 \\ Email dirk.matten@nottingham.ac.uk \\ http://www.nottingham.ac.uk/business/ICCSR
}





\title{
Manufacturing and Corporate Environmental Responsibility: Cost Implications of Voluntary Waste Minimisation
}

\author{
Wendy Chapple, Catherine J. Morrison Paul \& Richard Harris
}

\begin{abstract}
The issue of waste generation and its environmental implications raises important questions about firms' responsibilities. Regulations as well as firms' voluntary actions may result in waste reduction, but are costly to firms. Such costs may stem from "end of pipe" waste management, or from process solutions that involve changes in firms' input use. We evaluate county-level patterns of input use and output production in U.K. manufacturing, using a cost function approach that includes waste as a "bad output." We estimate the overall, inputspecific, and marginal production costs of reducing waste as shadow value, input demand, and marginal ("good output") cost elasticities with respect to this harmful output. We find for most counties that there are significant costs associated with waste reduction, that arise from increased intermediate materials but lower labour and capital demand.
\end{abstract}

\section{The Authors:}

Wendy Chapple is the Deputy Director of the International Centre for Corporate Social Responsibility at Nottingham University Business School and a Lecturer in Industrial Economics. Catherine J. Morrison Paul is a Professor in the Department of Agricultural and Resource Economics at the University of California at Davis and is currently involved in researching production structure, cost economics and productivity. Catherine is also the Associate Editor for the Journal of Productivity, American journal of Agricultural Economics, Agribusiness and Empirical Economics. Richard Harris is a Professor of Industrial and Regional Economics at the Department of Economics of the University of Durham.

\section{Address for correspondence:}

Wendy Chapple, Nottingham University Business School, Jubilee Campus, Wollaton Road, Nottingham, NG8 1BB, UK. E-mail: wendy.chapple@nottingham.ac.uk 



\section{Introduction}

In the last two decades waste has become an increasingly important environmental concern in most developed and developing countries. Fuelled by the Brundtland Report (World Commission of Environment and Development, 1987), the issue initially targeted was potential risks from waste to human health and the environment. The response to this by the U.K. government, as in many countries, was to legislate and use command and control frameworks to ensure safe disposal of waste, placing liability "from the cradle to the grave" and assigning duties for appropriate disposal. Attention has since shifted to the concept of a sustainable rate of waste generation, and the use of more market-oriented methods to regulate the disposal of waste.

In particular, a landfill tax was introduced in the U.K. in 1996 to encourage the reduction of waste. Set initially at a rate of 7 pounds per tonne, the aim of the tax was to internalise the externalities created by waste disposal in landfills, thus encouraging movement up the waste hierarchy to more sustainable waste practices such as recycling, reuse, and ultimately waste minimisation. Such a market mechanism provides incentives for firms to shift attention from end of pipe solutions to process solutions for waste minimisation, consistent with material flow principles (Pethig 2003) that are an increasing focus of sustainability. Viewing waste minimisation in the materials flow framework brings to the forefront firms' use of process inputs such as virgin and reused material, energy, and labour, rather than just waste management at the end of the process. That is, it underscores the role of production decisions and processes, and their likely changes in response to taxes or other forms of government intervention to stimulate waste reduction.

A growing number of firms have also chosen to go "above and beyond" legal requirements by engaging in recycling and abatement activities that further minimise waste and thus reduce environmental degradation. This behaviour, like actions such as initiating progressive human resource management programmes and embodying products with socially desirable attributes (such as dolphin free tuna or recycled paper), has become known as Corporate Social Responsibility (CSR: McWilliams and Siegel, 2001). Environmental CSR has manifested itself in several forms. Many firms have adopted voluntary environmental management 
systems, such as ISO14001, ${ }^{1}$ which have provided a vehicle for waste minimisation within firms. Others have signed international agreements such as the U.N. Global Compact, or have joined local initiatives such as envirowise ${ }^{2}$ waste minimisation clubs. A substantial rise in the level of environmental reporting has also been evident, either as a "stand alone" report or a part of the company reporting process. These trends have largely been driven by an increasing demand for "transparency" from stakeholders, and perceived consumer demand for environmental quality. Therefore firms have also used this medium to gain both reputational and market benefits from their environmental activities.(Arora and Cason, 1996) These activities can therefore be thought of as having both pecuniary and non-pecuniary motivations, but again involve increased production costs. Furthermore, the level of voluntary action might also be a function of the location of manufacturing, whereby economic prosperity, clustering of industry, geographical location and political activism might influence the levels of voluntary abatement (Arora and Cason, 1999). This suggests there might be location-specific "demand side" characteristics for waste abatement.

As waste management is related to production processes, analysis of waste practices and the potential for - and costs of - waste minimisation requires a "supply side" rather than a "demand side" approach (McWilliams and Siegel, 2001). This study develops such a framework, to characterize waste decisions by U.K. manufacturing firms in the context of production processes and costs, and thus in terms of their impacts on input use, output production, and efficiency, which are often the focus of debates about waste minimisation (Environment Agency, 2003).

\footnotetext{
${ }^{1}$ ISO 14001 is an environmental management system (EMS) introduced in 1996 by the International Standards Organisation. Firms are audited and accredited by independent accreditation agencies. Part of ISO 14001 is the process is firms setting their own environmental targets, however these targets are completely voluntary, and are not externally enforced or sanctioned.

2 There are over 100 active waste minimisation clubs across England \& Wales, providing advice to well over 5000 companies. The focus of these groups varies: some provide support to industries across a range of business sectors while others support specific sector groups. Their aim is to encourage reductions in resource use and waste emissions, and is supported by the environment agency.
} 
A primary goal of firms is the maximization of output production while minimising private costs. Minimising environmental costs may also be a key target, especially in response to pecuniary, social, or other incentives. Reaching these objectives involves making choices about waste generation, in combination with other production decisions. Like other forms of CSR, waste minimisation (reduction) would be expected both to reduce output production, since output and waste tend to be joint products, and to increase input costs, since more or better inputs are necessary to reduce wastage. Formally, these impacts of waste management may be characterized as (the primal notion of) lower output production from a given level of inputs, modeled via a production function, or (the dual counterpart of) higher input costs for a given level of output, from a cost function.

Input costs associated with reducing waste may also increase at the margin; firms with higher waste reduction levels incur higher implicit costs (shadow values) of waste management - or marginal waste reduction costs (Figure 1). Average costs of (good output) production may also be affected differently than marginal costs by waste management, thus affecting profit maximizing production decisions as well as scale economies. Cost impacts may also vary across inputs - or be biased. Biases might be absolute (if waste management involves increases in some and decreases in other inputs), or relative (e.g., increases in multiple inputs but by differing amounts).

For example, minimising waste can be capital intensive, as it often involves specific capital purchases such as pollution abatement (waste reduction) machinery. Firms employing higher levels of waste management technology will thus face higher capital costs, which may not be uniform across firms. Greater capital intensity for the provision of waste minimisation might in fact be associated with increased scale economies, due to the large fixed costs involved in waste management investment. ${ }^{3}$ In turn, labour costs could rise if more staff is required to implement, monitor, and engage in the additional required capital expenditures (McWilliams and Siegel, 2001).

The likely impact of waste minimisation on material flows seems more ambiguous. Based on the materials flow framework and the implied efficiency impacts of waste minimisation, reducing waste might lead to lower levels of primary, "virgin," or "new" material use, by encouraging reuse of materials within the production process. However, it alternatively might

\footnotetext{
${ }^{3}$ The higher are firms' output levels, the lower the per unit cost of the technology.
} 
be the case that reducing waste requires higher quality or more "processed" inputs, thus increasing the effective quantity (and thus price) of material inputs (McWilliams and Siegel 2001). This also raises questions about capital and labor impacts, since increased demand for more processed materials might reduce the demand for "value added" inputs formerly used for processing.

The overall cost implication of waste reduction depends on the balance of these input demand effects. If overall costs are higher (as one would expect, because otherwise waste reduction would have been cost-minimising before-hand), more stringent waste regulation or greater "demand" pressures for CSR from stakeholders could have significant implications for the cost structure and thus competitiveness of U.K. manufacturing firms. There are also likely to be spatial variations in these effects since companies in areas with higher marginal waste reduction costs, due to different types or density of production and population, will be less likely to reduce waste. ${ }^{4}$

To better understand and quantify the potential implications of waste reduction on U.K. manufacturing firms, we model regional cost, input demand, and output production patterns for this industry, and their connection with waste generation. Our framework is based on a flexible cost function, which permits the representation of a broad range of cost interactions and effects. We estimate these relationships econometrically using county by year panel data (42 counties in 1991-1998) for multiple outputs and inputs, including waste as an undesirable "bad" output. This model and data allow a detailed evaluation of production processes over time and space, and their link to the costs of waste reduction - or input- output- and spatialspecific patterns in the costs of environmental CSR activity and thus competitiveness.

We represent production costs associated with the reduction of waste by estimated shadow values for the "bad output" (waste) that embody the underlying effects on technology, and input and output composition. That is, they depend on the technological substitution possibilities and input demand and output supply behaviour of U.K. manufacturing firms that are captured in our empirical framework. These shadow values may be thought of as input cost savings from free disposal of waste (the marginal benefits of not being socially responsible), or, conversely, as the costs of this form of environmental CSR (waste

\footnotetext{
${ }^{4}$ Regional variations in supply and demand of waste disposal facilities may also cause waste disposal costs to vary, causing spatial variation in cost incentives for waste minimisation. Thus one might see different costs on the margin for different reasons due to different motivations to minimise waste.
} 
reduction). The corresponding factor-specific effects on the demands for inputs (labour, capital and materials) and the supply of products (good and bad outputs) are also estimated ,to assess whether waste reduction is labour or capital intensive, or leads to reductions in materials use or output production.

We find for the 60 percent of "regular" counties in our sample that there are costs associated with waste reduction that increase on the margin, arise from higher intermediate materials but lower labour and capital demand, and imply greater scale economies. For metropolitan counties, however, there is a strong labour-using, and in commuter belt counties a strong capital-saving, bias. These overall patterns imply that waste reduction requires more processed or higher quality materials, in turn resulting in less need for "value added" labour and capital inputs. However this is counteracted in varying amounts by movements toward more labour-intensive (less "dirty") production, and requirements for more waste-efficient or abatement capital. Different patterns across counties may be related to different levels and trends in heavy/light manufacturing, capital intensity, age of plant, and bad/good output ratios.

\section{Methodology}

\section{The Theoretical Model}

Measuring the costs and benefits of waste minimisation (reduction) in U.K. manufacturing involves explicitly modelling the production structure, recognising the wide variety of spatial and temporal output production and input cost patterns exhibited in the data. Our county level dataset includes information on the production of one "good" (aggregated) output and one "bad" (waste) output, and the use of three inputs (capital, labour and intermediate materials). The good output and input data are in the form of multilateral price and implicit quantity indices. The bad output, waste, is represented as a quantity only (due to problems obtaining accurate costs of disposal). Our estimation framework is based on a cost function model of U.K. manufacturing, which represents a broad array of interactions among the underlying inputs and outputs.

For empirical implementation the cost function is augmented by input demand equations defined by Shephard's lemma, and represents spatial, temporal, and industrial patterns by dummies for three different types of counties, a time trend, and industry characteristic variables. Including the quantity of waste (bad output) as an argument of the function, and 
thus of the system of estimating equations, allows us to examine not only the shadow values (overall cost effects) of waste, but also the impacts on input demands (including intermediate material use) and output production levels (marginal cost and scale/scope economies).

More specifically, the (total) cost function takes the general form $\mathrm{TC}=\mathrm{TC}\left(\mathrm{Q}_{\mathrm{G}}, \mathrm{Q}_{\mathrm{B}}, \mathbf{w}, \mathbf{D}, \mathrm{t}, \mathbf{C H}\right)$ where $\mathrm{Q}_{\mathrm{G}}$ is good output; $\mathrm{Q}_{\mathrm{B}}$ is bad output (waste); $\mathbf{w}$ is a vector of input prices $\mathrm{w}_{\mathrm{j}}$ (for capital, $\mathrm{X}_{\mathrm{K}}$, labour, $\mathrm{X}_{\mathrm{L}}$, and intermediate materials, $\mathrm{X}_{\mathrm{M}}$ ); $\mathbf{D}$ is a vector of county-type dummy variables; $\mathrm{t}$ is a time trend; and $\mathrm{CH}$ is a vector of county-specific manufacturing characteristics. The county dummy variables were included in an attempt to categorize three types of counties with very different patterns evident in the data; MET, COM, and CTY. These county types were distinguished according to intensity or clustering of production. Metropolitan areas (MET) are densely populated city areas, with high levels of manufacturing and a larger proportion of older ("dirty") industries. ${ }^{5}$ Commuter belt counties (COM) are close to London and have lower levels of manufacturing and high levels of residential landuse. Most "regular" counties (CTY) are between these two groups in terms of manufacturing clustering and residential land use. The industry characteristics included in $\mathbf{C H}$ - the average age of plants, $\mathrm{CH}_{\mathrm{AGE}}$, and the ratio of heavy to overall manufacturing output, $\mathrm{CH}_{\mathrm{SIC}}$ - were chosen for their significant cost-impacts and explanatory power for county-level cost variations in preliminary analysis. ${ }^{6}$

$\mathrm{Q}_{\mathrm{B}}$ is incorporated as an argument of the cost function to recognize that bad and good outputs are jointly produced; it is impossible to eliminate waste emissions while producing good output. "Free" or "unrestricted" production of bads (waste) thus allows firms to use less inputs to produce a given amount of $\mathrm{Q}_{\mathrm{G}}$, or to produce more $\mathrm{Q}_{\mathrm{G}}$ with a given input level, than if bads were limited. $^{7}$ That is, reducing waste is expected to be costly to producers in terms productivity - lower output per unit of input, or more inputs (costs) for a given amount of output - because it requires resources which ordinarily would be used in production of "good" outputs to be transferred to the task of minimising waste, such as through environmental management schemes, environmental audits and actual physical waste reduction (Fare et al

\footnotetext{
${ }^{5}$ These are listed as "metropolitan" areas in government statistics, and have city councils as opposed to county councils.

${ }^{6}$ Population density, R\&D intensity of the manufacturing industry, and ISO 14001 accreditations were also tried, but either had insignificant effects or exacerbated rather than attenuated the variability across counties.

${ }^{7}$ However, firms typically do not have to pay for this "bad output" and thus do not take it into account in their optimization process, so ".the environment is being used as an unpaid input by producers disposing of effluent" (Paul et al. 2002).
} 
1993). Conversely, however, it could be that the cost of waste minimisation is offset by material saving or enhanced "material efficiency," resulting in short run productivity gains and longer term technological change (Chapple and Harris, 2003).

As discussed in more detail below, these hypotheses about the productive or cost impacts of waste reduction may be addressed by evaluating the shadow cost (elasticity) of waste and its input- and output-specific components. That is, the shadow value or marginal waste reduction cost of $\mathrm{Q}_{\mathrm{B}}, \mathrm{SV}_{\mathrm{B}}=\partial \mathrm{TC} / \partial \mathrm{Q}_{\mathrm{B}}$, represents the overall cost-impact of reductions in $\mathrm{Q}_{\mathrm{B}}$. The input-and output-specific cost effects take the form of second order derivatives, because input demands (for $\mathrm{X}_{\mathrm{j}}, \mathrm{j}=\mathrm{K}, \mathrm{L}, \mathrm{M}$ ) and marginal production cost (of $\mathrm{Q}_{\mathrm{G}}, \mathrm{MC}_{\mathrm{G}}$ ) are first derivatives of $\mathrm{TC}(\bullet): \mathrm{X}_{\mathrm{j}}=\partial \mathrm{TC} / \partial \mathrm{w}_{\mathrm{j}}$ (by Shephard's lemma) and $\mathrm{MC}_{\mathrm{G}}=\partial \mathrm{TC} / \partial \mathrm{Q}_{\mathrm{G}}$. Input and output waste reduction effects may thus be represented by the impacts on $\mathrm{X}_{\mathrm{j}}$ and $\mathrm{MC}_{\mathrm{G}}$ from $\mathrm{Q}_{\mathrm{B}}$ changes or differences: $\partial \mathrm{X}_{\mathrm{j}} / \partial \mathrm{Q}_{\mathrm{B}}$ and $\partial \mathrm{MC}_{\mathrm{G}} / \partial \mathrm{Q}_{\mathrm{B}}$. For our analysis, these derivatives are expressed in terms of elasticities to represent their proportional impacts.

\section{The Data}

Our empirical analysis is carried out at the county level; we distinguish 42 counties or metropolitan areas. ${ }^{8}$ The primary motivation for using the county as the unit of analysis is that disposal targets and waste strategies are decided at this level (whereas collection decisions are made at the more disaggregated local authority level).

Our waste/production dataset merges information from the Annual Respondents Database (ARD) and the Chartered Institute of Public Finance and Accountancy (CIPFA) waste survey. The weighted ARD data are from Harris and Robinson (2002). The ARD collects data from 14000-19000 establishments, based on a stratified sampling frame. Because the collected data is heavily biased towards larger establishments (Oulton, 1997), sample weights for each establishment are calculated to ensure that they adequately reflect the underlying population distribution (Harris and Robinson, 2002). Weighting is also advantageous due to endogenous sampling (Harris, 2002); as the stratified sampling frame is based upon employment size, the probability of being in the sample is likely correlated with variables in the model.

\footnotetext{
${ }^{8}$ Two consistent outliers in the data, London and Warwickshire, were dropped from the analysis to avoid possible bias from outliers.
} 
The data on gross output (sales) and intermediate input (costs) were deflated using 1990based 4-digit information on producer prices for outputs and inputs. The plant and machinery estimates of the capital stock for each plant, and the price of capital (user cost of capital services), are taken from Harris and Drinkwater (2000). Labour quantity is reported as the number of full time workers, as reported in the ARD database and the price computed as total labour costs bill divided by this quantity.

The waste data were taken from the CIPFA waste survey of waste disposal authorities about waste collection and disposal. ${ }^{9}$ In the time period in question the response rate for this survey ranged from $70 \%$ in the early 1990 s to $81 \%$ in 1998 . The surveys were conducted at the local authority level for waste collection data and at the waste disposal authority (county) level for the waste generated/disposal statistics. Waste is reported in tonnes.

Summary statistics of the merged production/waste data for the full sample are provided in Table 1. Note that waste fell slightly between 1992 and 1997, with a sharp increase in 1998. This supports a criticism that the landfill tax meant to motivate waste reduction has been ineffectual (hence the change of the tax in 1998 to an escalating tax rate), ${ }^{10}$ although the waste-to-output ratio has remained reasonably constant overall (with some variation in 199596 driven by output changes). Gross output peaked in 1995, whereas both capital stock and employment have declined, and intermediate materials use (including outsourcing) has generally risen, during this time period. Prices of outputs and inputs have all increased throughout the period of analysis, with the price of capital rising and of materials falling relative to labour.

\section{Empirical Measures of Waste Reduction Effects}

As alluded to above, the marginal (input) costs of waste reduction may be measured as the shadow value of the bad output $\left(\mathrm{SV}_{\mathrm{QB}}=\partial \mathrm{TC} / \partial \mathrm{Q}_{\mathrm{B}}\right)$, expressed in proportional (elasticity) terms as $\varepsilon_{\mathrm{TC}, \mathrm{QB}}=\partial \ln \mathrm{TC} / \partial \ln \mathrm{Q}_{\mathrm{B}}=\mathrm{SV}_{\mathrm{QB}} \bullet \mathrm{Q}_{\mathrm{B}} / \mathrm{TC}$. That is, $-\varepsilon_{\mathrm{TC}, \mathrm{QB}}$ represents the proportion by which firms' input expenditures would have to increase (for a given "good" output level, $\mathrm{Q}_{\mathrm{G}}$ )

\footnotetext{
${ }^{9}$ Only English local authorities were considered, and those with significant missing data were dropped, leaving 42 included counties for 1991-98 (see Appendix table A1 for a list of the counties included).

${ }^{10}$ In the 1998 Budget, the UK Government announced a landfill tax "escalator", whereby the landfill tax would be increased to $£ 10$ in 1998 and increased by $£ 1$ a year until the tax reached $£ 15$ per tonne. The aim of this tax was to trigger investment in waste abatement technology.
} 
to reduce waste on the margin. Conversely, it represents the marginal (input) cost savings or benefits from unfettered waste generation/disposal - and thus the marginal amount firms would be willing to pay for the right to increase $\mathrm{Q}_{\mathrm{B}}$, or the tax that would be necessary to stimulate $\mathrm{Q}_{\mathrm{B}}$ reduction if it was not forthcoming voluntarily or directly legislated. The sign and significance of $\varepsilon_{\mathrm{TC}, \mathrm{QB}}$ is thus a fundamental issue to quantitatively explore in our analysis of the costs of waste reduction in U.K. manufacturing Further, whether this cost effect increases at the margin can be determined by the second order elasticity $\varepsilon_{\mathrm{SVB}, \mathrm{QB}}=\partial \ln \mathrm{SV}_{\mathrm{B}} / \partial \mathrm{ln}$ $\mathrm{Q}_{\mathrm{B}}=\left(-\partial^{2} \mathrm{TC} / \partial \mathrm{Q}_{\mathrm{B}}{ }^{2}\right) \cdot \mathrm{Q}_{\mathrm{B}} / \mathrm{SV}_{\mathrm{QB}}$.

Unlike technological (production function-based) measures of marginal products or primal shadow values, the $\varepsilon_{\mathrm{TC}, \mathrm{QB}}$ (cost-based) measure incorporates both technical substitution possibilities and the behavioural motivations underlying cost-efficient input choices. The overall cost effects represented by $\varepsilon_{\mathrm{TC}, \mathrm{QB}}$ can therefore be decomposed into input-specific demand effects, to facilitate the analysis of linkages among waste generation (reduction) and capital, labour, and materials use.

That is, based on Shepherds lemma, demand for input $k$ is characterized by $\mathrm{X}_{\mathrm{j}}=\partial \mathrm{TC} / \partial \mathrm{w}_{\mathrm{j}}$ $(\mathrm{j}=\mathrm{K}, \mathrm{L}, \mathrm{M})$. Input demand changes associated with increased (decreased) waste are therefore represented by the second order derivatives $\partial \mathrm{X}_{\mathrm{j}} / \partial \mathrm{Q}_{\mathrm{B}}=\partial^{2} \mathrm{TC} / \partial \mathrm{w}_{\mathrm{j}} \partial \mathrm{Q}_{\mathrm{B}}$. A more interpretable (unitless) representation of such a relationship is its proportional counterpart - the input demand elasticity $\varepsilon_{\mathrm{Xj}, \mathrm{QB}}=\partial \ln \mathrm{X}_{\mathrm{j}} / \partial \ln \mathrm{Q}_{\mathrm{B}}$. For $\mathrm{j}=\mathrm{M}$, for example, $\varepsilon_{\mathrm{XM}, \mathrm{QB}}$ reflects the dependence of material use on the (allowed or chosen) level of waste disposal, and hence the link between materials efficiency and waste minimisation. Similarly, $\varepsilon_{\mathrm{XK}, \mathrm{QB}}$ and $\varepsilon_{\mathrm{XL}, \mathrm{QB}}$ capture the $\mathrm{X}_{\mathrm{K}^{-}}$and $\mathrm{X}_{\mathrm{L}}$-specific impacts of waste reduction. Assessment of input demand and composition (or intensity) responses to waste management changes thus involves evaluation and comparison of the $\varepsilon_{\mathrm{Xj}, \mathrm{QB}}$ measures.

For example, the overall cost effect of $\mathrm{Q}_{\mathrm{B}}, \varepsilon_{\mathrm{TC}, \mathrm{QB}}$, will be negative if waste reduction is costly; reducing $\mathrm{Q}_{\mathrm{B}}$ increases input costs. If $\mathrm{X}_{\mathrm{M}}$ (materials) and $\mathrm{Q}_{\mathrm{B}}$ (waste) are joint or complementary, as would be implied if waste minimisation involves reuse and minimisation of "virgin" materials, or increased "materials efficiency," $\varepsilon_{\mathrm{XM,QB}}$ would instead be positive. In this case an input bias in absolute terms is implied; if overall costs increase but material demand declines with waste reduction, the use of $X_{K}$ and $X_{L}$ must increase even more than 
suggested by the total cost elasticity. That is, $\varepsilon_{\mathrm{XL}, \mathrm{QB}}$ and $\varepsilon_{\mathrm{XK}, \mathrm{QB}}$ are likely to both be not only negative, but also more negative than $\varepsilon_{\mathrm{TC}, \mathrm{QB}}\left(\varepsilon_{\mathrm{Xj}, \mathrm{QB}}<\varepsilon_{\mathrm{TC}, \mathrm{QB}}<0, \mathrm{j}=\mathrm{K}, \mathrm{L}\right)$. If $\varepsilon_{\mathrm{XM}, \mathrm{QB}}$ is instead negative, this may imply that higher (perhaps more processed) materials demand is associated with waste reduction. However, the magnitude of this elasticity is still unlikely to be the same as $\varepsilon_{\mathrm{TC}, \mathrm{QB}}$ or the other input-specific elasticities. In particular, if all $\varepsilon_{\mathrm{Xj}, \mathrm{QB}}$ elasticities are negative but are different sizes, relative input biases are apparent; cost increases from waste reduction may be input $j$-saving relative to input $i$. These relationships may also vary across different types of counties or industries. Assessing these input demand relationships and biases with respect to waste reduction thus provides a broad range of information for evaluation of $\mathrm{Q}_{\mathrm{B}}$ cost effects.

Measuring the impact on the marginal cost of the good output $\left(\mathrm{Q}_{\mathrm{G}}\right)$ from restrictions on waste $\left(\mathrm{Q}_{\mathrm{B}}\right)$ provides further insights about the input- and output- specific costs of waste reduction. That is, the shadow or marginal cost of good output production is represented by its marginal costs: $\mathrm{MC}_{\mathrm{G}}=\partial \mathrm{TC} / \partial \mathrm{Q}_{\mathrm{G}}$. The impact of $\mathrm{Q}_{\mathrm{B}}$ changes on marginal cost, $\partial \mathrm{MC}_{\mathrm{G}} / \partial \mathrm{Q}_{\mathrm{B}}=$ $\partial^{2} \mathrm{TC} / \partial \mathrm{Q}_{\mathrm{G}} \partial \mathrm{Q}_{\mathrm{B}}$ or in elasticity form, $\varepsilon_{\mathrm{MCG}, \mathrm{QB}}=\partial \ln \mathrm{MC}_{\mathrm{G}} / \partial \ln \mathrm{Q}_{\mathrm{B}}$, thus reflects firms' motivations to adapt output production levels in order to reduce waste. Perhaps even more importantly, this measure also allows us to evaluate the implied change in scale economies associated with waste reduction. That is, since scale economies are measured in a cost framework as $\varepsilon_{\mathrm{TC}, \mathrm{QG}}=\partial \mathrm{ln} \mathrm{TC}_{\mathrm{G}} / \partial \mathrm{ln} \mathrm{Q}_{\mathrm{G}}=\mathrm{MC}_{\mathrm{G}} / \mathrm{AC}$ (where $\mathrm{AC}$ is average costs), if $\mathrm{MC}_{\mathrm{G}}$ falls $\left(\varepsilon_{\mathrm{MCG}, \mathrm{QB}}>0\right)$ and/or $\mathrm{AC}$ rises $\left(\varepsilon_{\mathrm{TC}, \mathrm{QB}}<0\right)^{11}$ at higher waste reduction levels, scale economies are correspondingly greater. The $\varepsilon_{\mathrm{MCG}, \mathrm{QB}}$ measure may also be interpreted in terms of scope economies, since scope economies (diseconomies) imply that when one "output" level increases the marginal cost of the other output declines (rises).

\section{Econometric Implementation and Results}

\section{The Estimating Model}

The cost function from the model overviewed above thus takes the general form $\mathrm{TC}=$ $\mathrm{TC}\left(\mathrm{Q}_{\mathrm{G}}, \mathrm{Q}_{\mathrm{B}}, \mathrm{w}_{\mathrm{K}}, \mathrm{w}_{\mathrm{L}}, \mathrm{w}_{\mathrm{M}}, \mathrm{D}_{\mathrm{MET}}, \mathrm{D}_{\mathrm{COM}}, \mathrm{D}_{\mathrm{CTY}}, \mathrm{t}, \mathrm{CH}_{\mathrm{AGE}}, \mathrm{CH}_{\mathrm{SIC}}\right)$, where the vector notation has been expanded to make explicit the individual arguments of the function. Econometric implementation of the model, and construction of the parametric elasticity measures

\footnotetext{
${ }^{11}$ This measure is positive rather than negative because the shadow value elasticity is defined here as the negative derivative to facilitate interpretation of the measure as the costs of waste reduction.
} 
summarizing waste reduction costs, requires specifying a functional form for $\mathrm{TC}(\cdot)$. We approximate this function by a generalised Leontief form, with output levels and shift factors in quadratic form, as in Paul (2001):

$$
\begin{aligned}
& \mathrm{TC}\left(\mathrm{Q}_{\mathrm{G}}, \mathrm{Q}_{\mathrm{B}}, \mathrm{w}_{\mathrm{K}}, \mathrm{w}_{\mathrm{L}}, \mathrm{w}_{\mathrm{M}}, \mathrm{D}_{\mathrm{MET}}, \mathrm{D}_{\mathrm{COM}}, \mathrm{D}_{\mathrm{CTY}}, \mathrm{t}, \mathrm{CH}_{\mathrm{AGE}}, \mathrm{CH}_{\mathrm{SIC}}\right)=\sum_{\mathrm{j}} \sum_{\mathrm{i}} \alpha_{\mathrm{ji}} \mathrm{w}_{\mathrm{j}}^{0.5} \mathrm{w}_{\mathrm{i}}^{0.5} \\
& +\sum_{\mathrm{j}} \sum_{\mathrm{m}} \delta_{\mathrm{jm}} \mathrm{w}_{\mathrm{j}} \mathrm{Q}_{\mathrm{m}}+\sum_{\mathrm{j}} \sum_{\mathrm{r}} \delta_{\mathrm{jk}} \mathrm{w}_{\mathrm{j}} \mathrm{E}_{\mathrm{k}} \\
& +\sum_{\mathrm{j}} \mathrm{w}_{\mathrm{j}}\left(\sum_{\mathrm{m}} \sum_{\mathrm{n}} \gamma_{\mathrm{mn}} \mathrm{Q}_{\mathrm{m}} \mathrm{Q}_{\mathrm{n}}+\sum_{\mathrm{m}} \sum_{\mathrm{k}} \gamma_{\mathrm{mk}} \mathrm{Q}_{\mathrm{m}} \mathrm{E}_{\mathrm{k}}+\sum_{\mathrm{k}} \sum_{\mathrm{l}} \gamma_{\mathrm{kl}} \mathrm{E}_{\mathrm{k}} \mathrm{E}_{\mathrm{l}}\right)
\end{aligned}
$$

where $i, j$ denote the inputs, $m, n$ the good and bad outputs, and $k, l$ the external (denoted "E") factors t, D, and $\mathbf{C H}$. Our system of estimating equations is comprised of this cost function, combined with three factor demand equations derived from (1) $\left(\mathrm{X}_{\mathrm{j}}=\partial \mathrm{TC} / \partial \mathrm{w}_{\mathrm{j}}\right.$ from Shephard's lemma, $\mathrm{j}=\mathrm{K}, \mathrm{L}, \mathrm{M}){ }^{12}$ and was estimated using seemingly unrelated regression (SUR) econometric procedures in PC-TSP (the parameter estimates are presented in Appendix Table A2). This approach is often preferred to an instrumental variable approach, which can lead to mis-specification and can cause serious problems with panel data. ${ }^{13}$

Potential heteroskedasticity was accommodated by computing robust-White standard errors, and autoregressive (AR1) errors were allowed for initially, but had virtually no impact on the results and so were left out of the final model. County level dummy variables (fixed effects) were also incorporated in preliminary empirical investigation, but contributed to instability of the parameter estimates and thus volatility of the elasticity estimates without substantively affecting the overall or county-type patterns, and so were also omitted for our final "preferred" model. Also, we retained in the model only those $\delta_{\mathrm{jk}}, \gamma_{\mathrm{mk}}$, and $\gamma_{\mathrm{kl}}$ estimates for the county dummies that had t-statistics exceeding 1 , since many were very insignificant.

The elasticity estimates discussed in the previous section depend on a variety of parameters and their associated standard errors, because they are based on a somewhat complex flexible function form. Computing standard errors for the elasticities is thus problematic, particularly

\footnotetext{
${ }^{12}$ By construction the cost function is homogeneous of degree one, so the input demand equations are homogeneous of degree zero.

${ }^{13}$ As discussed in Paul and MacDonald (2003), the choice of instruments is typically arbitrary and can generate volatility in the estimates that are exacerbated in a system of equations. There also can be issues when an autoregressive structure is explicitly incorporated, especially when lags of the exogenous variables are used (although for our model we omitted the autoregressive adjustment).
} 
when the cross-section dimension of the panel spans very different types of entities (in this case counties), so evaluating the elasticities at the mean of the data (using the "delta method") is not very meaningful. ${ }^{14}$ It is therefore quite common in the cost literature to see such elasticities summarized simply as the mean of the elasticity estimates across all (or a subset of) observations. However, it is desirable to derive confidence intervals for the elasticities to allow for statistical inference. One possible approach is to present estimates of statistical significance by county, but this is cumbersome and thus not very informative overall. We chose, therefore, to use bootstrap methods to generate distributions and thus confidence intervals for our elasticity estimates. ${ }^{15}$ Since this is not a common practice in this literature, it deserves further elaboration.

\section{Bootstrapping the cost function}

The concept of the bootstrap was first introduced in the seminal piece by Efron (1979) to provide new perspective to the established statistical technique of jack knifing and calculate (non-parametrically or parametrically) the distribution and thus standard error of a statistic. We applied the non-parametric approach, which directly reflects the structure of the data because it does not require an assumption about the form of the distribution. ${ }^{16}$ The non parametric bootstrap represents the discrete empirical distribution generated by a random sample of size $\mathrm{n}$ from an unknown distribution $\mathrm{F}$. This empirical distribution of $\hat{F}_{n}$ assigns equal probability to each sample item. ${ }^{17}$ By generating an random sequence or resample from the distribution $\hat{F}_{n}$, or its smoothed version, we generate estimates of the original distribution.

To develop the bootstrap standard error and bias estimators, let $\hat{\theta_{n}}$ be a statistic based on the observed sample, from the unknown distribution function $\mathrm{F}$, that estimates some real-valued

\footnotetext{
${ }^{14}$ Differences between the average values of the elasticities and the elasticities evaluated at the average values of the data, as found in our initial estimation, might arise because the assumed normal approximation does not account for possible skewness of the marginal distributions of the parameters, in addition to the wide variance across the sample.

${ }^{15}$ Bickel and Freedman (1981) formulated conditions for the consistency of the bootstrap, resulting in extensions of the Efron model to a broad range of standard applications, and argued for the use of the bootstrap because it does not require theoretical derivations such as functional derivatives, influence functions, and asymptotic variances. Singh (1981) also demonstrated that the bootstrap estimator of the sampling distribution of a given statistic might be more accurate than the traditional normal approximation, so the bootstrap may be particularly useful when there is some uncertainty as to the correctness of traditional methods of estimation.

${ }^{16}$ The distribution is usually assumed to be normal, but our estimated elasticities evaluated at the mean values of the data suggested that a normality assumption for these data might not be warranted.

${ }^{17}$ For the parametric bootstrap setting we would consider $\mathrm{F}$ to be a member of some prescribed parametric family and obtain $\hat{F}_{n}$ by estimating the family parameters from the data.
} 
parameter of interest $\theta$ with standard error and bias $\operatorname{se}_{F}\left(\hat{\theta_{n}}\right)$ and $\operatorname{bias}_{F}\left(\hat{\theta_{n}}\right)$. Since the form of the statistic $\hat{\theta_{n}}$ might be very complicated, the exact formulas to compute the true standard error $(B E S E)$ and bias $(B E B)$ might be very difficult to derive. Bootstrap estimation approximates these measures with the help of multiple resamples.

The approximation to the standard error estimate suggested by Efron (1979) is:

$$
s \hat{e}_{\mathbf{B}}=\left\{\sum_{b=1}^{B}\left[\hat{\theta}^{*}(b)-\hat{\theta}^{*}{ }_{n}(.)\right]^{2} /(B-1)\right\}^{1 / 2}
$$

where $\hat{\theta}_{n}^{*}(b)$ is the original statistic $\hat{\theta}_{n}$ calculated from the bth resample $(\mathrm{b}=1 \ldots \mathrm{B}), \hat{\theta}_{n}^{*}()=$. $\sum_{b=1}^{B} \hat{\theta}_{n}^{*}(b) / B$, and $\mathrm{B}$ is the total number of resamples (each of size $\mathrm{n}$ ). By the law of large numbers:

$$
\lim _{\mathrm{B} \rightarrow \infty} s \hat{e}_{B}=\operatorname{BESE}\left(\hat{\theta}_{n}\right),
$$

and for a sufficiently large $\mathrm{n}$ :

(4) $\operatorname{BESE}\left(\hat{\theta}_{n}\right) \approx \operatorname{se}_{F}\left(\hat{\theta_{n}}\right)$.

Similarly, the approximation of the bias $b \hat{i} a_{B}$, based upon the B resamples, can be calculated by:

$$
\hat{b i a s}_{B}=\sum_{b=1}^{B} \hat{\theta}_{n}^{*}(b) / B-\hat{\theta}_{n} .
$$

The higher the " $\mathrm{B}$ " the higher the accuracy of the BESE and estimators. Typically, $\mathrm{B}=250$ gives a satisfactory approximation of the standard error, whereas for the bias $\mathrm{B}$ may have to be significantly higher (Efron and Tibisharani, 1993). We chose $B=5000$, which is computationally demanding but gives us highly accurate approximations. 
The data for our application is panel in nature and hence is not completely independent, so an extension of the Efron bootstrap is required. We adapted the "block" bootstrap method suggested by Künsch (1989) to do a "panel" bootstrap; the random sampling takes place within "blocks," which in our case are the county observations. So, within the $\mathrm{X}_{1 \ldots \ldots . . .} \mathrm{X}_{\mathrm{n}}$ observations in our data, where $\hat{\theta_{n}}\left(X_{1} \ldots . . X_{n}\right)$ denotes the real valued statistic, we created $l$ blocks, where $l$ is the number of counties, each containing t years of observations. Then, for each block, we resampled randomly inside the block, resulting in pseudo values for B.

\section{The Bootstrap Results}

Based on the parameters of the "base" model (equation 1 estimated by SUR), we first estimated the elasticities of interest for each observation, and averaged them across the overall sample and each county division (MET, COM, CTY), resulting in the "mean elasticity estimates" $\varepsilon_{\mathrm{TC}, \mathrm{QB}}, \varepsilon_{\mathrm{SVB}, \mathrm{QB}}, \varepsilon_{\mathrm{XL}, \mathrm{QB}}, \varepsilon_{\mathrm{XK}, \mathrm{QB}}, \varepsilon_{\mathrm{XM}, \mathrm{QB}}, \varepsilon_{\mathrm{TC}, \mathrm{Qg}}, \varepsilon_{\mathrm{MCG}, \mathrm{QB}}, \varepsilon_{\mathrm{SVB}, \mathrm{Dt}}$, and $\varepsilon_{\mathrm{SVB}, \mathrm{CH}} . \quad$ For comparison and to construct standard errors, we alternatively used a bootstrapping algorithm (within PC-TSP) to randomly resample within the "blocks" of our data, and reran the cost function with the resulting replications of the parameters and elasticity estimates of interest recorded; that is, $\varepsilon_{\mathrm{TC}, \mathrm{QB}}^{*}, \varepsilon_{\mathrm{SVB}, \mathrm{QB}}^{*}, \varepsilon_{\mathrm{XL}, \mathrm{QB}}^{*}, \varepsilon_{\mathrm{XK}, \mathrm{QB}}^{*}, \varepsilon_{\mathrm{XM}, \mathrm{QB}}^{*}, \varepsilon_{\mathrm{TC}, \mathrm{Qg}}^{*} \varepsilon^{*}{ }_{\mathrm{MCG}, \mathrm{QB}}, \varepsilon^{*}{ }_{\mathrm{SVB}, \mathrm{Dt}}$, and $\varepsilon^{*} \mathrm{SVB,CH}$ are recorded for the bootstrap $b=1 \ldots \mathrm{B}$. We then calculated the average values, standard errors, and biases associated with these estimates, across the whole sample and separately for the different county types. The results of both the base and bootstrap estimation are reported in tables $5-8$, with the full distributions of $\varepsilon^{*} \mathrm{TC}, \mathrm{QB}, \varepsilon^{*} \mathrm{XL}, \mathrm{QB}, \varepsilon^{*} \mathrm{XK}, \mathrm{QB}$, and $\varepsilon^{*} \mathrm{XM}, \mathrm{QB}$, graphed in Figures 2-5.

First consider the full sample elasticity estimates in Table 5. Both the mean $\varepsilon_{\mathrm{TC}, \mathrm{QB}}$ elasticities from the original SUR estimation and the bootstrapped means are negative, and from the distribution of $\varepsilon^{*} \mathrm{TC}, \mathrm{QB}$ it is evident that there is 0.99 probability of $\varepsilon^{*} \mathrm{TC}, \mathrm{QB}$ taking a negative value. Thus, lower waste emission levels correspond to higher costs, as expected. The bootstrap estimate is also very close to the mean elasticity estimate in size, so averaging the estimated elasticities across observations is supported. These shadow costs are also decreasing in waste, as indicated by the negative $\varepsilon_{\mathrm{SVB}, \mathrm{QB}}$ estimate. ${ }^{18}$ That is, at higher

\footnotetext{
${ }^{18}$ Note that the average bootstrap measure $\varepsilon_{\mathrm{SVB}, \mathrm{QB}}$ is actually positive, but the probability of it being negative is .98; the positive mean is driven by just a few very positive outliers, as suggested by the very high "bootstrap max" in the fifth column. Second order derivatives of external factors tend in general to have large outliers, because the first derivative appears in the denominator of the elasticity, so if there are any outliers close to zero
} 
abatement (waste reduction) levels the marginal abatement cost rises, consistent with convex and increasing marginal waste reduction costs, as in Figure 1.

The mean input elasticities reveal that average $\varepsilon_{\mathrm{XL}, \mathrm{QB}}$ and $\varepsilon_{\mathrm{XK}, \mathrm{QB}}$ are both positive for the entire sample, with $\varepsilon_{\mathrm{XL}, \mathrm{QB}}$ nearly twice as large as $\varepsilon_{\mathrm{XK}, \mathrm{QB}}(0.126$ versus 0.073$)$. The bootstrapped means are also positive and very close to the same size (0.133 and 0.070$)$, and have a very high probability of being positive ( 0.99 and 0.90 respectively). These estimates indicate that lower levels of waste abatement (more waste emissions) imply higher levels of labour and capital use. This implication is somewhat perplexing; as the usual expectation is that $\varepsilon_{\mathrm{XL}, \mathrm{QB}}$ and $\varepsilon_{\mathrm{XK}, \mathrm{QB}}$ would be negative - that waste reduction is labour- and capital-using. However, if abatement or reduction of waste involves increases in the use of more processed rather than primary materials, this could cause less demand for these "value added" inputs. This result could alternatively (or in part) also be a result of aggregating dissimilar counties, resulting in somewhat misleading overall averages, as discussed further below.

The estimated sign of $\varepsilon_{\mathrm{XM}, \mathrm{QB}}$ is negative (and consistent across the base and bootstrap models, with average estimates of -0.120 and -0.118 , respectively, and a probability of being negative that is essentially 1.0). That is, waste abatement appears to be material-using, as opposed to material-saving as suggested by the material flow balance approach. This result is again contrary to our initial expectations, although it is consistent with the notion that waste reduction involves increasing the use of more processed or higher quality inputs - materials composition impacts not well represented by our data.

These input composition effects are obviously biased in both absolute and relative terms; that is, the average input-specific measures differ in sign as well as size from the average overall cost elasticity $\varepsilon_{\mathrm{TC}, \mathrm{QB}}$, so input composition is strongly linked to waste emissions. For example, for the bootstrap measures, $\varepsilon^{*} \mathrm{TC}, \mathrm{QB}=-0.035$. The implied increase in cost from waste reduction implies higher materials demand, $\varepsilon^{*} \mathrm{XM}, \mathrm{QB}=-0.118$, but the change in $\mathrm{X}_{\mathrm{M}}$ is greater than overall costs so waste abatement is both absolutely and relatively materials-using. In turn, $\varepsilon^{*} \mathrm{XL}, \mathrm{QB}=0.133$ and $\varepsilon^{*} \mathrm{XK}, \mathrm{QB}=0.073$ reflect absolute capital and labour saving biases,

the second order derivatives will be greatly inflated. For these elasticities, therefore, it is preferable to focus on the confidence interval. 
although the overall increase in materials use outweighs these capital and labour saving effects.

Moving to the output relationships, $\varepsilon_{\mathrm{MCG}, \mathrm{QB}}=0.191\left(\varepsilon^{*}{ }_{\mathrm{MCG}, \mathrm{QB}}=0.183\right)$ is large and positive (with probability 1.0), which indicates that the marginal costs of production increase with waste levels, or greater waste reduction is consistent with lower marginal production costs. This could be due to high levels of fixed inputs associated with waste abatement, or, given the largely panel nature of the data, that counties with lower (higher) marginal production costs produce less (more) waste. ${ }^{19}$ Implications about the link between waste generation and scale economies can also be drawn, because $\varepsilon_{\mathrm{TC}, \mathrm{QB}}$ indicates the impact of higher $\mathrm{Q}_{\mathrm{B}}$ levels on average costs (since $\mathrm{Q}_{\mathrm{G}}$ is constant by construction). Our mean elasticity estimates suggest increasing returns to scale in the production of good outputs; average $\varepsilon_{\mathrm{TC}, \mathrm{QG}}=0.975<1$ or $\mathrm{MC}<\mathrm{AC}$. Our positive (average) $\varepsilon_{\mathrm{MCG}, \mathrm{QB}}$ and negative $\varepsilon_{\mathrm{TC}, \mathrm{QB}}$ estimates show that waste reduction is consistent with lower marginal and higher average costs, implying that scale economies are even greater at higher waste abatement levels.

\section{County-Type Patterns}

The bootstrap results in table 5 show that the mean elasticity estimates from the SUR estimation provide relevant indications of the size as well as signs of the key elasticities for our analysis. The signs of the input-specific elasticities raise questions, however, about how much these results might reflect the temporal versus the spatial, or county, dimension of the data. In particular, these results might be generated by differences across county types, rather than reflecting the costs of increasing waste reduction in any particular county. The results in Tables 6-8 show that the elasticity estimates do vary significantly across our county subcategories. The mean elasticity and bootstrap estimates are still closely comparable, suggesting robust models at the disaggregated level. However, there are noticeable differences in estimates between county types, the main differences being the demands for inputs by the "regular" (CTY) as compared to the metropolitan (MET) and commuter belt (COM) counties. The bootstrap bias is also much lower for the individual county types, suggesting that disaggregation is appropriate for estimating meaningful elasticity values.

\footnotetext{
${ }^{19}$ This can be interpreted in terms of scope economies; if MC increases with waste generation there are, in some sense, diseconomies of scope. If defined in terms of "good" outputs - increased waste abatement implies lower $\mathrm{MC}$ - this may be thought of as scope economies.
} 
The CTY results are reported in table 6. Comparison between the mean elasticity from the original estimation and the bootstrap results, and consideration of the bootstrap bias compared to the overall sample results, show that the results are robust and have a high level of precision. $\varepsilon_{\mathrm{TC}, \mathrm{QB}}$ remains negative (with a 1.0 probability), and is larger (in absolute value) than for the overall results, so reducing waste implies significant input costs (both statistically and in terms of magnitude). $\varepsilon_{\mathrm{SVB}, \mathrm{QB}}$ is again negative in terms of the mean elasticity estimate and the bootstrap probability ( 0.98 probability of a negative elasticity), although not for the bootstrap mean due to large positive outliers. The larger (in absolute value) $\varepsilon_{\mathrm{SVB}, \mathrm{QB}}$ estimate also suggests that abatement costs are increasing on the margin even more for CTY than other counties. And $\varepsilon_{\mathrm{MCG}, \mathrm{QB}}$ is still positive (although slightly smaller than overall); counties in the CTY category with higher marginal production costs have higher waste levels (lower levels of abatement), or $\mathrm{MC}_{\mathrm{G}}$ increases as waste generation levels rise.

The input elasticities $\varepsilon_{\mathrm{XL}, \mathrm{QB}}$ and $\varepsilon_{\mathrm{XL}, \mathrm{QB}}$ are also the same sign but larger (in absolute value) than for the average county, whereas $\varepsilon_{\mathrm{XK}, \mathrm{QB}}$ reverses sign $\left(\varepsilon_{\mathrm{XK}, \mathrm{QB}}=-0.035\right.$ and $\varepsilon^{*}{ }_{\mathrm{XK}, \mathrm{QB}}=-$ 0.033 , with a .82 probability of being negative). The (absolute) labour-saving and (relative) materials-using biases of waste reduction are thus still evident. But we find in this case an absolute capital-using but relative capital-saving bias (the reduction in $\mathrm{X}_{\mathrm{K}}$ associated with higher $\mathrm{Q}_{\mathrm{B}}$ is less than the cost effect, due to the large materials-using bias). The greater capital demand associated with higher waste abatement levels suggests that waste reduction requires capital inputs that are either specific to waste abatement or are more "efficient" in terms of waste.

The metropolitan counties (MET) contain large "city" areas, with a high concentration of manufacturing, as well as (typically) older "dirtier" industries. The results for these counties are presented in Table 7. $\varepsilon_{\mathrm{TC}, \mathrm{QB}}$ is again negative (with a probability of 0.98 ), but slightly smaller (in absolute value) than for the overall sample average, indicating that the proportionate increase in cost from waste abatement is less than for the "regular" counties. $\varepsilon_{\mathrm{SVB}, \mathrm{QB}}$ is also positive, in contrast to the overall and CTY measures, although this average is driven by a few large outliers; the probability of this measure being negative for these counties is 0.99 . 
Differences in the input demand and output marginal cost patterns from the other counties are also apparent. The estimated $\varepsilon_{\mathrm{Xj}, \mathrm{QB}}$ elasticities for all inputs are negative, implying that waste abatement is labour, capital and material using in an absolute sense, although it is only relatively labor-using. $\varepsilon_{\mathrm{XL}, \mathrm{QB}}$ is greater (in absolute value) than $\varepsilon_{\mathrm{TC}, \mathrm{QB}}$, whereas the capital and materials elasticities are smaller than the overall cost measure. The labor impact is thus a key difference that could be related to a greater labor-intensity of the older industries. Finally, $\varepsilon_{\mathrm{MCG}, \mathrm{QB}}$ is positive but even larger than at the CTY and overall levels, suggesting strong impacts of waste reduction on economies of scale.

The final county category, the commuter belt counties (COM), is typified by high levels of residential land use and low levels of light manufacturing. Not surprisingly this affects the potential for and costs of waste abatement; $\varepsilon_{\mathrm{TC}, \mathrm{QB}}$ for these counties is positive (but with a probability of only 0.76 ), indicating lower rather than higher costs with increased waste reduction. Also, average $\varepsilon_{\mathrm{SVB}, \mathrm{QB}}$ is negative and large (in absolute value, -0.944), suggesting that the cost-savings benefits of waste reductions are reduced quite significantly, and ultimately turn into enhanced costs, at higher levels of waste abatement. By contrast, the (good) output marginal cost and scale economy implications of waste reduction are very similar to the overall results.

The positive $\varepsilon_{\mathrm{TC}, \mathrm{QB}}$ may arise from waste disposal difficulties from the high levels of residential land use in these areas, and the associated costs, but in terms of the production estimates it is driven by a (relative and absolute) capital saving bias of waste reduction. That is, the input elasticities mirror the overall results that waste reduction is (absolutely) labour and capital saving, and material using, so waste abatement requires more (quantity or quality) of intermediate materials, and less labour and capital inputs. However, an important difference here is the magnitudes of the elasticities; the (positive) $\varepsilon_{\mathrm{XK}, \mathrm{B}}$ elasticity is so large relative to the (negative) $\varepsilon_{\mathrm{XM}, \mathrm{QB}}$ elasticity that it drives the overall finding of cost-savings from waste reduction both in the COM counties and for the average across all counties.

The above discussion reveals strong differences across our three county types in terms of costs, input use and scale effects. Manufacturing production in the CTY category faces the highest costs from waste abatement, whereas that in the COM category incurs a negative cost, implying a cost "benefit" from waste minimisation. On the input side, waste abatement for all 
three types of counties is (absolutely) materials-using, but for the CTY and MET categories it is also capital-using, and only for the MET counties is it labour-using. For the outputs, production in all counties is subject to increasing returns to scale in good outputs that is augmented by waste abatement. To further assess the differences across county types it is useful to consider what county characteristics, revealed from summary statistics for the different types of counties in Tables 2-4, might contribute to differences in the costs and input demands associated with waste reduction.

First, note that counties in the MET category have higher levels of both good and bad (waste) outputs, followed by the CTY and then the COM categories. However the ratio of waste to good outputs has improved for the CTY and MET counties from 1991 to 1998; it has fallen the most (by 19 percent, although strong yearly fluctuations are evident) in the CTY category, but the manufacturing industries in the MET counties have achieved a 5 percent reduction. The COM counties by contrast have a significantly higher level of waste per unit of output, which has increased by 21 percent. Hence, the differences in estimated waste reduction costs may be influenced by a combination of the absolute and relative levels of both production and abatement; the higher the level of abatement the higher the cost, consistent with Figure 1.

The ability to reduce waste will also be linked to other industry-specific characteristics. One influence might be the "heaviness" of manufacturing; heavier manufacturing processes may produce more waste, and hence have higher waste per unit of good output simply because of the nature of the process. In particular, although the COM counties have lower absolute output levels, the concentration of heavy to light industries is the highest. In addition to the heavy-light manufacturing ratio, the average plant age and the capital intensity ratio (capital/labour) seem likely to influence the input mix used, and hence costs of waste reduction. Average plant age has fallen drastically during the sample period, as is evident from Tables 1-4, although plant age is highest in the MET counties and has dropped the most in the COM counties. Capital intensity is also lowest in the COM, and highest in the CTY, counties. These patterns might provide insights about why waste reduction is more laborusing in the MET, and capital-saving in the COM, counties, as postulated briefly below, although counteracting influences are suggested and the linkages between the industry characteristics and costs of waste reduction are not transparent. 


\section{Concluding Remarks}

In this paper we have explored, across U.K. counties and for 1991-1998, cost and input use changes associated with reductions in waste (bad output) generation. Our results provide insights about the impacts on competitiveness from waste abatement resulting from either pecuniary motivations or environmental CSR.

Overall, we find that waste reduction is associated with increased costs; the shadow value of waste reduction is negative and statistically significant. We also find these costs to be increasing at the margin; the second-order elasticity of the cost function is negative with respect to waste (although a few significant outliers make the average elasticity positive in some cases), and counties with higher (lower) waste levels have lower (higher) abatement costs. In fact, the measured shadow value for the commuter belt (COM) counties, which have both the highest levels of waste to output and an upward trend in waste generation, is actually positive. In addition, waste reduction for all counties corresponds to lower marginal costs and greater scale economies.

In terms of input use, we find that the cost of waste reduction is invariably associated with increased materials use (although less so for COM and especially metropolitan, MET, than for "regular," CTY, counties). This is inconsistent with a materials efficiency story, such as that from a materials flow framework, but consistent with the idea that more processed or higher quality materials are required to minimise waste.

For labor, we find that lower waste levels are related to lower labor use (waste reduction is absolutely labor-saving), except for the MET counties which have a strong labor-using bias. This may imply substitution of materials for labor; if more processed materials are used, less in-plant processing, and thus labor, is required.

For capital, we find for all except the COM counties that waste reduction is capital-using capital expenditures seem required for higher levels of waste-abatement - although not as much so as for materials. This is consistent with the idea that more waste-efficient or wasteabatement machinery may be required to minimise waste. However, the finding that waste reduction is associated with lower capital levels for the COM counties - waste minimisation is capital-saving - is sufficiently strong that it drives an overall capital-saving average result across all counties. This may imply that, as for labor, increased use of processed materials 
reduces the need for processing facilities in the plant, counteracting (at least for some areas or industries) the tendency for waste reduction to require capital investment.

In sum, the results for the CTY counties (25 of our 42 counties, or 60 percent), show strong tendencies for waste reduction to "use" materials and "save" labor, and a less significant tendency to use capital. This seems intuitively reasonable; more processed or higher quality materials are needed to reduce waste, and this implies less "value added" labor and capital inputs are needed, although increased demand for abatement or more materials-efficient capital counteracts that tendency sufficiently that waste reduction is absolutely (but not relatively) capital-using. The variations from this story in the MET (6 or 14 percent of the counties) and COM (11 or 26 percent) categories are not as readily interpretable.

The discrepancies in the results for these counties may be due to their differing characteristics, although the mechanism through which this works is not obvious from a look at countyspecific variables that might have explanatory power. For example, COM counties have the highest levels of heavy to light manufacturing. This intuitively seems to imply greater capital intensity, although capital/labour and capital/materials ratios are in fact lower in these than in the CTY and MET counties. The greater reliance on materials and labor in the COM counties may help to explain why waste reduction is associated with less capital in these counties; waste reduction seems to require lower materials use, and if materials needs are high this may require significant substitution efforts. That is, the large requisite materials- and labor-using adaptations for waste reduction in the CTY and MET counties, respectively, may be less possible when production is already relatively materials and labor intensive. This may mean significant amounts of capital must be freed up from producing capital-intensive heavy intermediate materials required for heavy manufacturing production, in order to support increased materials demand in the COM counties.

In terms of vintage, all counties have exhibited a strongly falling age of plant, but the age is slightly higher in the MET counties. These counties also tend to be more manufacturingintensive, and to be where older more "dirty" types of manufacturing production are located. The finding of labor-using waste reduction in these counties may imply that newer capital that is meant to be less "dirty" is also more labor-intensive. The relatively lower and more rapidly declining age of the plants in the COM counties seem to confirm the very different capitalusing tendency of the manufacturing industries in these counties. 
Note also that although the MET and COM results are very different, labor and capital "move together" in both these counties with waste reduction; the fact that they move in opposite directions (waste reduction implies increased labor and capital for MET and the opposite for $\mathrm{COM}$ ) may in part be due to the different levels and trends in waste disposal in these counties. They could also be associated with the high (low) manufacturing-intensities of the MET (COM) counties. Finally, note that the strong tendencies for waste reduction to be labor-using in the MET counties and capital-saving in the COM counties imply that waste reduction measures or voluntary implementation may reduce the manufacturing capital intensity in such counties.

This evidence is therefore in concurrence with the McWilliams and Siegel (2001) theory of the firm perspective of CSR. Our results support their proposition that CSR (in this case waste reduction) is costly, and the higher the levels of abatement the higher are marginal costs. We also find evidence to support their proposition that the provision of CSR (waste reduction) is capital and material using, and that because of high fixed costs that there are scale economies in CSR (waste reduction). These findings have significant implications for the competitiveness and performance of UK manufacturing. The provision of waste reduction as a CSR activity will very much be dependant on how much consumers, members of the supply chain and other stakeholders value the activity of waste minimisation. If products are successfully differentiated through levels of "environmental responsibility," and waste reduction is valued by consumers or other companies in the supply chain, levels of demand and prices should rise for products with this attribute. If the increase in revenue is greater than the increase in costs, we would expect to see rising levels of waste reduction. However, if revenue does not cover these costs, we would expect to see a decline in waste abatement activity, as competitiveness and performance are reduced.

\section{References}

Arora, S. and T. Cason. 1996. "Why do firms Volunteer to Exceed Environmental Regulations? Understanding Participation in EPA's 33/50 Program." Land Economics. 72(4):413-32.

Arora, S. and T. Cason. 1999. "Do Community Characteristics Influence Environmental Outcomes? Evidence from the Toxics Release Inventory." Southern Economic Journal. 65(4):691-716.

Bickel, P. and Freedman, D. 1981."Some asymptotic theory of the bootstrap." Annals of Statistics. 9:1196-1217. 
Chapple, W. and R. Harris. 2003. "Accounting for waste in Regional Productivity Measurement." ICCSR working paper series, Nottingham University Business School, No. 01-2003

Efron, B. 1979. "Bootstrap. Another look at the Jackknife." Annuals of Statistics. 7(1):1-26.

Efron, B. and R. Tibshirani. 1993. An Introduction to Bootstrap. Chapman and Hall, New York.

Fare, R., S. Grosskopf, K. Lovell, and S. Yaisawarang. 1993. "Derivation of Shadow Prices for Undesirable Outputs: A Distance Function Approach." Review of Economics and Statistics. 75(2):374-380.

Harris, R.I.D and S. Drinkwater. 2000. "U.K. Plant and Machinery Capital Stocks and Plant Closures." Oxford Bulletin of Economics and Statistics. 62:239-261.

Harris, R.I.D. 2002. "Foreign Ownership and Productivity in the United Kingdom- Some Issues When Using ARD Establishment Level Data." Scottish Journal of Political Economy.49(3):318-335.

Künsch, H. 1989. "The jackknife and the bootstrap for general stationary observations." Annals of Statistics. 17:1217-1241.

McWilliams, A. and D. Siegel 2001. "Corporate Social Responsibility: A Theory of the Firm Perspective." Academy of Management Review, 26(1):117-127.

Oulton, N., 1997. "The ABI respondents database: A new resource for industrial economics research." Economic Trends, 528:46-57.

Paul, C.J.M. 2001. "Market and Cost Structure in the US Beef Packing Industry: A PlantLevel Analysis.” American Journal of Agricultural Economics. 83(1):64-76.

Paul, C.J.M., V.E. Ball, R.G. Felthoven, and R.F. Nehring. 2002. "Effective costs and Chemical Use in United States Agricultural Production: Using the Environment as a 'Free' Input.' American Journal of Agricultural Economics. 84(4):902-915.

Paul, C.J.M. and J.R. MacDonald. 2003. "Tracing the Effects of Agricultural Commodity Prices and Food Costs.” American Journal of Agricultural Economics. 85(3):633-646

Pethig, R. 2003. "The 'materials balance approach' to pollution: its origin, implications and acceptance" Volkswirtschaftliche Diskussionsbeitraege from Universitaet Siegen, Fachbereich Wirtschaftswissenschaften:105-03.

Singh, K. 1981. “On the asymptotic accuracy of Efron's bootstrap." Annals of Statistics. 9(6): 1187-1195.

World Commission of Environment and Development. 1987. The Brundtland Report: Our Common Future. Oxford University Press. New York. 
Table 1: National Cost Data

\begin{tabular}{|l|r|r|r|r|r|r|r|r|}
\hline & 1991 & 1992 & 1993 & 1994 & 1995 & 1996 & 1997 & 1998 \\
\hline Gross Output (£Mill) $^{\mathrm{a}}$ & 126521 & 129390 & 118578 & 140558 & 152799 & 102017 & 134000 & 131153 \\
\hline Waste (000 tonnes) $^{\mathrm{b}}$ & 13576 & 13007 & 12575 & 13027 & 13108 & 13074 & 13058 & 13489 \\
\hline Capital (£ Mill) $^{\mathrm{a}}$ & 44717 & 52220 & 46835 & 47389 & 37992 & 25493 & 29618 & 31784 \\
\hline Labour(000 FTE) $^{\mathrm{a}}$ & 1887 & 1817 & 1556 & 1543 & 1593 & 972 & 1287 & 1463 \\
\hline Material (£ Mill) $^{\mathrm{a}}$ & 82214 & 86289 & 78577 & 91362 & 103782 & 72575 & 99657 & 99387 \\
\hline Capital Price (index) $^{\mathrm{a}}$ & 0.350 & 0.353 & 0.375 & 0.623 & 0.807 & 0.608 & 1.158 & 1.099 \\
\hline Labour Price $^{\mathrm{a}}$ & 0.017 & 0.017 & 0.018 & 0.019 & 0.020 & 0.021 & 0.019 & 0.023 \\
\hline Material Price $^{\mathrm{a}}$ & 1.019 & 1.028 & 1.060 & 1.088 & 1.138 & 1.142 & 1.068 & 1.065 \\
\hline Good Output Price $^{\mathrm{a}}$ & 1.033 & 1.050 & 1.075 & 1.102 & 1.169 & 1.188 & 1.191 & 1.295 \\
\hline Average age of plant $^{\mathrm{a}}$ & 19.82 & 19.28 & 19.49 & 16.65 & 13.63 & 11.90 & 10.96 & 10.36 \\
\hline Heavy/ light manuf $^{\mathrm{a}}$ & 1.64 & 1.76 & 1.68 & 2.18 & 2.30 & 1.97 & 2.54 & 2.09 \\
\hline
\end{tabular}

a. Data from the Annual Respondents Database (ARD), from the Office of National Statistics UK.

b. Data from the Chartered Institute of Public Financial Accountants Annual Digest of Waste Collection and Disposal Statistics.

Table 2: County Category (CTY)

\begin{tabular}{|l|r|r|r|r|r|r|r|r|}
\hline & 1991 & 1992 & 1993 & 1994 & 1995 & 1996 & 1997 & 1998 \\
\hline Gross Output (£Mill) & 53994 & 54181 & 52103 & 61361 & 67507 & 43072 & 56398 & 61132 \\
\hline Waste (000 tonnes) & 5761 & 5649 & 5377 & 5456 & 5378 & 5425 & 5350 & 5307 \\
\hline Capital (£ Mill) & 21175 & 28477 & 25312 & 25942 & 17667 & 12350 & 12933 & 15024 \\
\hline Labour(000 FTE) & 806 & 769 & 679 & 672 & 706 & 421 & 530 & 661 \\
\hline Material (£ Mill) & 34112 & 35637 & 34035 & 38554 & 45195 & 30583 & 42224 & 46084 \\
\hline Capital Price (index) & 0.322 & 0.317 & 0.359 & 0.620 & 0.879 & 0.592 & 1.194 & 1.151 \\
\hline Labour Price & 0.016 & 0.017 & 0.017 & 0.019 & 0.019 & 0.021 & 0.020 & 0.023 \\
\hline Material Price & 1.018 & 1.026 & 1.059 & 1.087 & 1.132 & 1.140 & 1.059 & 1.053 \\
\hline Good Output Price & 1.035 & 1.052 & 1.075 & 1.103 & 1.174 & 1.191 & 1.190 & 1.254 \\
\hline Average age of plant & 19.94 & 19.44 & 19.52 & 16.73 & 13.60 & 11.88 & 11.22 & 10.68 \\
\hline Heavy/ light manuf & 1.45 & 1.55 & 1.53 & 2.01 & 2.03 & 1.75 & 2.36 & 1.92 \\
\hline
\end{tabular}


$\mathrm{n}=25$

$1+1$

1

$1+$ 
Table 3: Metropolitan Category (MET)

\begin{tabular}{|l|r|r|r|r|r|r|r|r|}
\hline & 1991 & 1992 & 1993 & 1994 & 1995 & 1996 & 1997 & 1998 \\
\hline Gross Output (£Mill) & 37632 & 39916 & 36979 & 43005 & 46207 & 30593 & 38594 & 37950 \\
\hline Waste (000 tonnes) & 3779 & 3566 & 3406 & 3623 & 3716 & 3725 & 3575 & 3633 \\
\hline Capital (£ Mill) & 13511 & 13861 & 13186 & 12412 & 12148 & 7876 & 9386 & 9738 \\
\hline Labour(000 FTE) & 615 & 602 & 519 & 513 & 515 & 323 & 419 & 463 \\
\hline Material (£ Mill) & 25355 & 27448 & 25160 & 29032 & 32191 & 22197 & 29734 & 30363 \\
\hline Capital Price (index) & 0.266 & 0.274 & 0.319 & 0.480 & 0.560 & 0.457 & 0.774 & 0.770 \\
\hline Labour Price & 0.016 & 0.017 & 0.018 & 0.019 & 0.020 & 0.021 & 0.019 & 0.022 \\
\hline Material Price & 1.014 & 1.021 & 1.050 & 1.084 & 1.152 & 1.142 & 1.078 & 1.076 \\
\hline Good Output Price & 1.031 & 1.044 & 1.085 & 1.101 & 1.168 & 1.191 & 1.224 & 1.240 \\
\hline Average age of plant & 20.69 & 19.72 & 20.41 & 17.83 & 15.21 & 13.89 & 12.32 & 12.11 \\
\hline Heavy/ light manuf & 1.47 & 1.47 & 1.51 & 1.72 & 1.95 & 2.01 & 1.39 & 2.11 \\
\hline n=6 & & & & & & & & \\
\hline
\end{tabular}

Table 4: Commuter Belt Category (COM)

\begin{tabular}{|l|r|r|r|r|r|r|r|r|}
\hline & 1991 & 1992 & 1993 & 1994 & 1995 & 1996 & 1997 & 1998 \\
\hline Gross Output (£Mill) & 34894 & 35292 & 29495 & 36190 & 39084 & 28351 & 39007 & 32069 \\
\hline Waste (000 tonnes) & 4035 & 3791 & 3791 & 3947 & 4013 & 3922 & 4132 & 4547 \\
\hline Capital (£ Mill) & 10030 & 9881 & 8336 & 9034 & 8176 & 5265 & 7299 & 7021 \\
\hline Labour(000 FTE) & 467 & 446 & 357 & 357 & 371 & 228 & 338 & 339 \\
\hline Material (£ Mill) & 22745 & 23203 & 19382 & 23775 & 26395 & 19794 & 27698 & 22939 \\
\hline Capital Price (index) & 0.448 & 0.466 & 0.434 & 0.700 & 0.786 & 0.714 & 1.279 & 1.161 \\
\hline Labour Price & 0.018 & 0.019 & 0.019 & 0.020 & 0.021 & 0.023 & 0.020 & 0.025 \\
\hline Material Price & 1.023 & 1.036 & 1.068 & 1.092 & 1.145 & 1.147 & 1.08 & 1.084 \\
\hline Good Output Price & 1.031 & 1.051 & 1.072 & 1.099 & 1.159 & 1.183 & 1.178 & 1.407 \\
\hline Average age of plant & 19.16 & 18.76 & 18.97 & 15.90 & 12.90 & 10.97 & 9.78 & 8.86 \\
\hline Heavy/ light manuf & 2.09 & 2.30 & 2.08 & 2.75 & 3.03 & 2.40 & 3.47 & 2.42 \\
\hline n=11 & & & & & & & & \\
\hline
\end{tabular}


Table 5: Overall Sample Results

\begin{tabular}{|l|l|l|l|l|l|l|l|}
\hline Measure & $\begin{array}{l}\text { Mean } \\
\text { Elasticity } \\
\text { Estimate }\end{array}$ & Bootstrap & $\begin{array}{l}\text { Bootstrap } \\
\text { Standard } \\
\text { Error and } \\
\text { Bootstrap } \\
\text { Bias }\end{array}$ & $\begin{array}{l}\text { Bootstrap } \\
\text { Min and } \\
\text { Max }\end{array}$ & $\begin{array}{l}\text { Skewness } \\
\text { Kurtosis }\end{array}$ & Var & Prob \\
\hline$\varepsilon_{\mathrm{TC}, \mathrm{QB}}$ & -0.038 & -0.035 & 0.018 & 0.020 & -0.021 & 0.0003 & $-=0.97$ \\
& & & 0.004 & -0.094 & 0.026 & & \\
\hline$\varepsilon_{\mathrm{SVB}, \mathrm{QB}}$ & -1.109 & 0.700 & 8.63 & -33.87 & 13.63 & 74.63 & $-=0.98$ \\
& & & 1.8 & 172.23 & 245.42 & & \\
\hline$\varepsilon_{\mathrm{XL}, \mathrm{QB}}$ & 0.126 & 0.133 & 0.036 & -0.015 & -0.020 & 0.001 & $+=0.99$ \\
& & & 0.008 & 0.265 & 0.145 & & 9 \\
\hline$\varepsilon_{\mathrm{XK}, \mathrm{QB}}$ & 0.073 & 0.070 & 0.050 & -0.093 & -0.123 & 0.0025 & $+=0.90$ \\
& & & -0.045 & 0.236 & 0.002 & & \\
\hline$\varepsilon_{\mathrm{XM}, \mathrm{QB}}$ & -0.120 & -0.118 & 0.020 & -0.1887 & -0.0341 & 0.0004 & $-=1.0$ \\
& & & 0.1 & -0.0496 & 0.0158 & & \\
\hline$\varepsilon_{\mathrm{TC}, \mathrm{QG}}$ & 0.975 & 0.975 & 0.017 & 0.916 & 0.047 & 0.0003 & $+=1.0$ \\
& & & 0 & 1.03 & 0.024 & & \\
\hline$\varepsilon_{\mathrm{MCG}, \mathrm{QB}}$ & 0.191 & 0.183 & 0.031 & 0.088 & 0.079 & 0.0009 & $+=1.0$ \\
& & & -0.008 & 0.287 & 0.0416 & & \\
\hline
\end{tabular}


Table 6: Results for the "regular" counties: CTY

\begin{tabular}{|l|l|l|l|l|l|l|l|}
\hline Measure & $\begin{array}{l}\text { Mean } \\
\text { Elasticity } \\
\text { Estimate }\end{array}$ & Bootstrap & $\begin{array}{l}\text { Bootstrap } \\
\text { Standard } \\
\text { Deviation } \\
\text { \& }\end{array}$ & $\begin{array}{l}\text { Bootstrap } \\
\text { Min and } \\
\text { Max }\end{array}$ & $\begin{array}{l}\text { Skewness } \\
\text { Kurtosis }\end{array}$ & Var & Prob \\
& & & $\begin{array}{l}\text { Bootstrap } \\
\text { Bias }\end{array}$ & & & & \\
\hline$\varepsilon_{\mathrm{TC}, \mathrm{QB}}$ & -0.077 & -0.072 & 0.026 & 0.013 & -0.124 & 0.0007 & $-=0.99$ \\
& & & 0.005 & -0.150 & -0.033 & & \\
\hline$\varepsilon_{\mathrm{SVB}, \mathrm{QB}}$ & -1.662 & 0.287 & 10.429 & -58.62 & 17.22 & 108.78 & $-=0.98$ \\
& & & 1.949 & 258.718 & 403.86 & & \\
\hline$\varepsilon_{\mathrm{XL}, \mathrm{QB}}$ & 0.176 & 0.187 & 0.050 & 0.031 & 0.043 & 0.0025 & $+=1.0$ \\
& & & 0.016 & 0.340 & 0.037 & & \\
\hline$\varepsilon_{\mathrm{XK}, \mathrm{QB}}$ & -0.035 & -0.033 & 0.065 & -0.273 & -0.096 & 0.004 & $-=0.82$ \\
& & & 0.002 & 0.155 & -0.035 & & \\
\hline$\varepsilon_{\mathrm{XM}, \mathrm{QB}}$ & -0.174 & -0.170 & 0.026 & -0.265 & -0.034 & 0.0006 & $-=1.0$ \\
& & & 0.004 & -0.084 & 0.074 & & \\
\hline$\varepsilon_{\mathrm{TC}, \mathrm{QG}}$ & 0.924 & 1.002 & 0.020 & 0.932 & -0.011 & 0.0004 & $+=1.0$ \\
& & & 0.05 & 1.07 & 0.1778 & & \\
\hline$\varepsilon_{\mathrm{MCG}, \mathrm{QB}}$ & 0.132 & 0.126 & 0.218 & 0.0604 & 0.052 & 0.0004 & $+=1.0$ \\
& & & -0.006 & 0.1992 & 0.0248 & & \\
\hline
\end{tabular}


Table 7: Results for the metropolitan counties: MET

\begin{tabular}{|c|c|c|c|c|c|c|c|}
\hline Measure & $\begin{array}{l}\text { Mean } \\
\text { Elasticity } \\
\text { Estimate }\end{array}$ & Bootstrap & $\begin{array}{l}\text { Bootstrap } \\
\text { Standard } \\
\text { Deviation } \\
\& \\
\text { Bootstrap } \\
\text { Bias }\end{array}$ & $\begin{array}{l}\text { Bootstrap } \\
\text { Min and } \\
\text { Max }\end{array}$ & $\begin{array}{l}\text { Skewness } \\
\text { Kurtosis }\end{array}$ & Var & Prob \\
\hline$\varepsilon_{\mathrm{TC}, \mathrm{QB}}$ & -0.027 & -0.024 & $\begin{array}{l}0.031 \\
0.003\end{array}$ & $\begin{array}{l}0.120 \\
-0.129\end{array}$ & $\begin{array}{l}-0.121 \\
0.565\end{array}$ & 0.0009 & $-=0.77$ \\
\hline$\varepsilon_{\mathrm{SVB}, \mathrm{QB}}$ & 0.775 & 3.120 & $\begin{array}{l}41.91 \\
2.345\end{array}$ & $\begin{array}{l}-145.17 \\
1212.45\end{array}$ & $\begin{array}{l}24.51 \\
695.27\end{array}$ & $\begin{array}{l}1756.8 \\
4\end{array}$ & $-=0.99$ \\
\hline$\varepsilon_{\mathrm{XL}, \mathrm{QB}}$ & -0.070 & -0.070 & $\begin{array}{l}0.084 \\
0\end{array}$ & $\begin{array}{l}-0.384 \\
0.210\end{array}$ & $\begin{array}{l}-0.002 \\
0.023\end{array}$ & 0.007 & - $=0.98$ \\
\hline$\varepsilon_{\mathrm{XK}, \mathrm{QB}}$ & -0.025 & -0.016 & $\begin{array}{l}0.052 \\
0.009\end{array}$ & $\begin{array}{l}-0.194 \\
0.171\end{array}$ & $\begin{array}{l}0.010 \\
0.067\end{array}$ & 0.003 & - $=0.96$ \\
\hline$\varepsilon_{\mathrm{XM}, \mathrm{QB}}$ & -0.017 & -0.015 & $\begin{array}{l}0.025 \\
0.0015\end{array}$ & $\begin{array}{l}-0.1070 \\
0.113\end{array}$ & $\begin{array}{l}-0.149 \\
0.972\end{array}$ & 0.0006 & $-=0.95$ \\
\hline$\varepsilon_{\mathrm{TC}, \mathrm{QG}}$ & 0.968 & 0.994 & $\begin{array}{l}0.0324 \\
0.026\end{array}$ & $\begin{array}{l}0.906 \\
1.105\end{array}$ & $\begin{array}{l}0.325 \\
-0.0464\end{array}$ & 0.001 & $+=1.0$ \\
\hline$\varepsilon_{\mathrm{MCG}, \mathrm{QB}}$ & 0.326 & 0.313 & $\begin{array}{l}0.053 \\
-0.0127\end{array}$ & $\begin{array}{l}0.154 \\
0.491\end{array}$ & $\begin{array}{l}0.054 \\
0.035\end{array}$ & 0.002 & $+=1.0$ \\
\hline
\end{tabular}


Table 8: Results for the commuter belt counties: COM

\begin{tabular}{|c|c|c|c|c|c|c|c|}
\hline Measure & $\begin{array}{l}\text { Mean } \\
\text { Elasticity } \\
\text { Estimate }\end{array}$ & Bootstrap & $\begin{array}{l}\text { Bootstrap } \\
\text { Standard } \\
\text { Deviation } \\
\& \\
\text { Bootstrap } \\
\text { Bias }\end{array}$ & $\begin{array}{l}\text { Bootstrap } \\
\text { Min and } \\
\text { Max }\end{array}$ & $\begin{array}{l}\text { Skewness } \\
\text { Kurtosis }\end{array}$ & Var & Prob \\
\hline$\varepsilon_{\mathrm{TC}, \mathrm{QB}}$ & 0.034 & 0.034 & $\begin{array}{l}0.030 \\
0\end{array}$ & $\begin{array}{l}0.109 \\
-0.0505\end{array}$ & $\begin{array}{l}-0.102 \\
-0.336\end{array}$ & 0.0008 & $+=0.76$ \\
\hline$\varepsilon_{\mathrm{SVB}, \mathrm{QB}}$ & -0.944 & 0.301 & $\begin{array}{l}6.34 \\
1.245\end{array}$ & $\begin{array}{l}-79.18 \\
107.608\end{array}$ & $\begin{array}{l}5.87 \\
139.38\end{array}$ & 40.25 & $-=0.99$ \\
\hline$\varepsilon_{\mathrm{XL}, \mathrm{QB}}$ & 0.125 & 0.130 & $\begin{array}{l}0.062 \\
0.005\end{array}$ & $\begin{array}{l}-0.094 \\
0.305\end{array}$ & $\begin{array}{l}-0.194 \\
0.162\end{array}$ & 0.004 & $+=0.95$ \\
\hline$\varepsilon_{\mathrm{XK}, \mathrm{QB}}$ & 0.339 & 0.262 & $\begin{array}{l}0.155 \\
-0.077\end{array}$ & $\begin{array}{l}-0.194 \\
0.579\end{array}$ & $\begin{array}{l}-0.983 \\
-0.143\end{array}$ & 0.024 & +0.83 \\
\hline$\varepsilon_{\mathrm{XM}, \mathrm{QB}}$ & -0.063 & -0.063 & $\begin{array}{l}0.028 \\
0\end{array}$ & $\begin{array}{l}-0.152 \\
0.012\end{array}$ & $\begin{array}{l}-0.152 \\
-0.239\end{array}$ & 0.0008 & $-=1.0$ \\
\hline$\varepsilon_{\mathrm{TC}, \mathrm{QG}}$ & 0.944 & 0.910 & $\begin{array}{l}0.023 \\
-0.34\end{array}$ & $\begin{array}{l}0.818 \\
0.976\end{array}$ & $\begin{array}{l}-0.116 \\
-0.07\end{array}$ & 0.0005 & $+=1.0$ \\
\hline$\varepsilon_{\mathrm{MCG}, \mathrm{QB}}$ & 0.239 & 0.228 & $\begin{array}{l}0.04 \\
-0.011\end{array}$ & $\begin{array}{l}0.1066 \\
0.359\end{array}$ & $\begin{array}{l}0.138 \\
0.037\end{array}$ & 0.0016 & $+=1.0$ \\
\hline
\end{tabular}


Figure 1: Marginal Waste Reduction

Cost

$$
£ \text { per }
$$

tonne

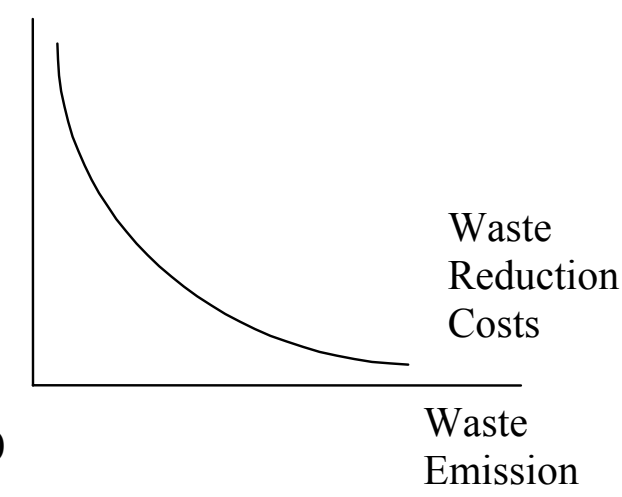


Figure 2: $\varepsilon_{\mathrm{TC}, \mathrm{QB}}$ from the overall estimates

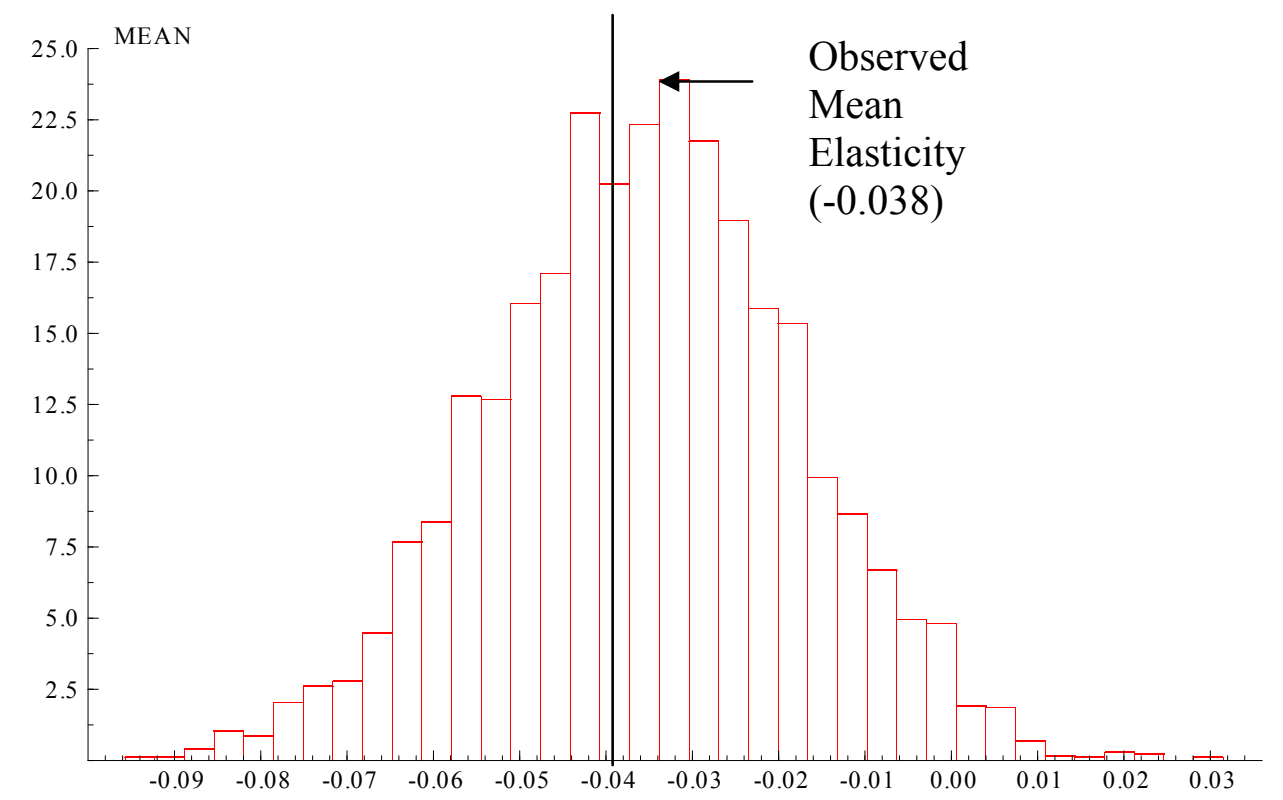


Fig 3: $\varepsilon_{\mathrm{XL}, \mathrm{QB}}$ from the overall estimates

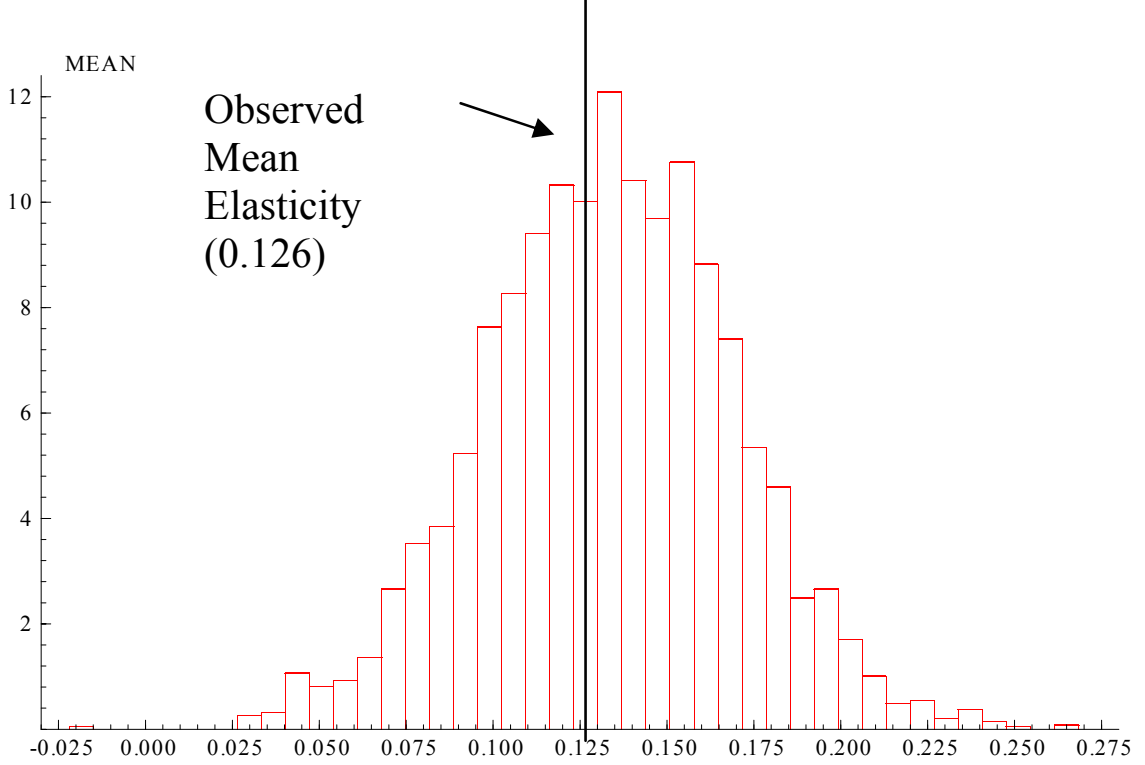


Fig 4: $\varepsilon_{\mathrm{XK}, \mathrm{QB}}$ from the overall estimates.

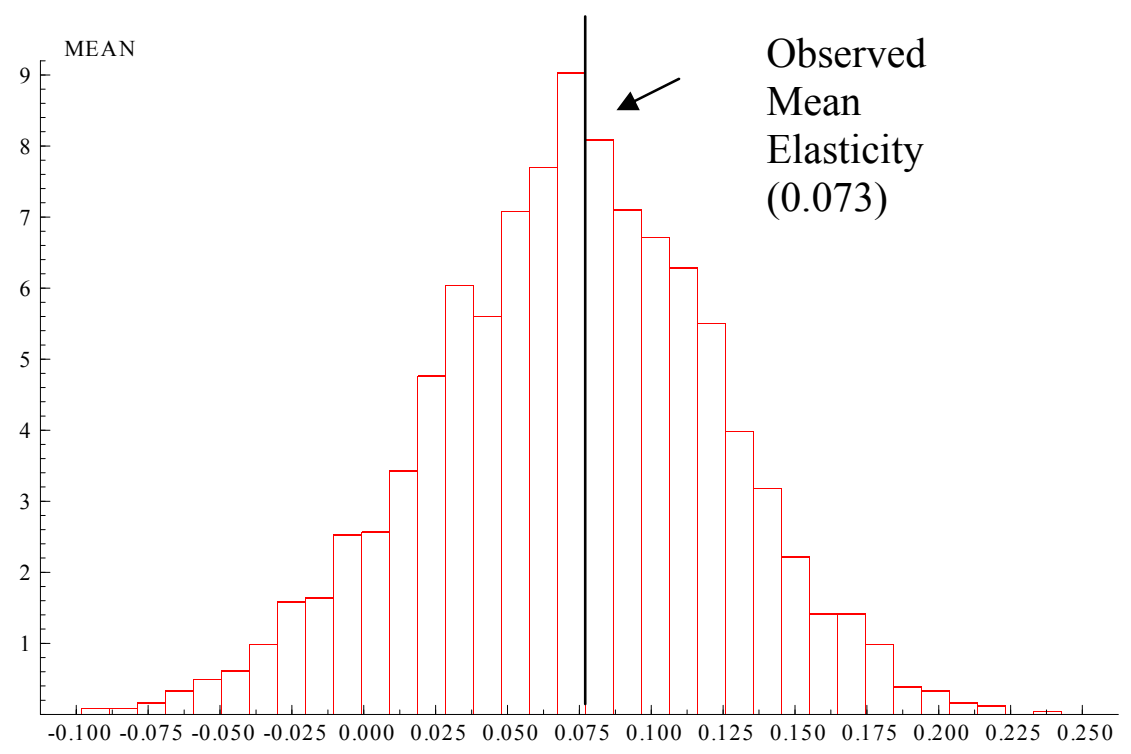


Figure 5: $\varepsilon_{\mathrm{XM}, \mathrm{QB}}$ from the overall estimates.

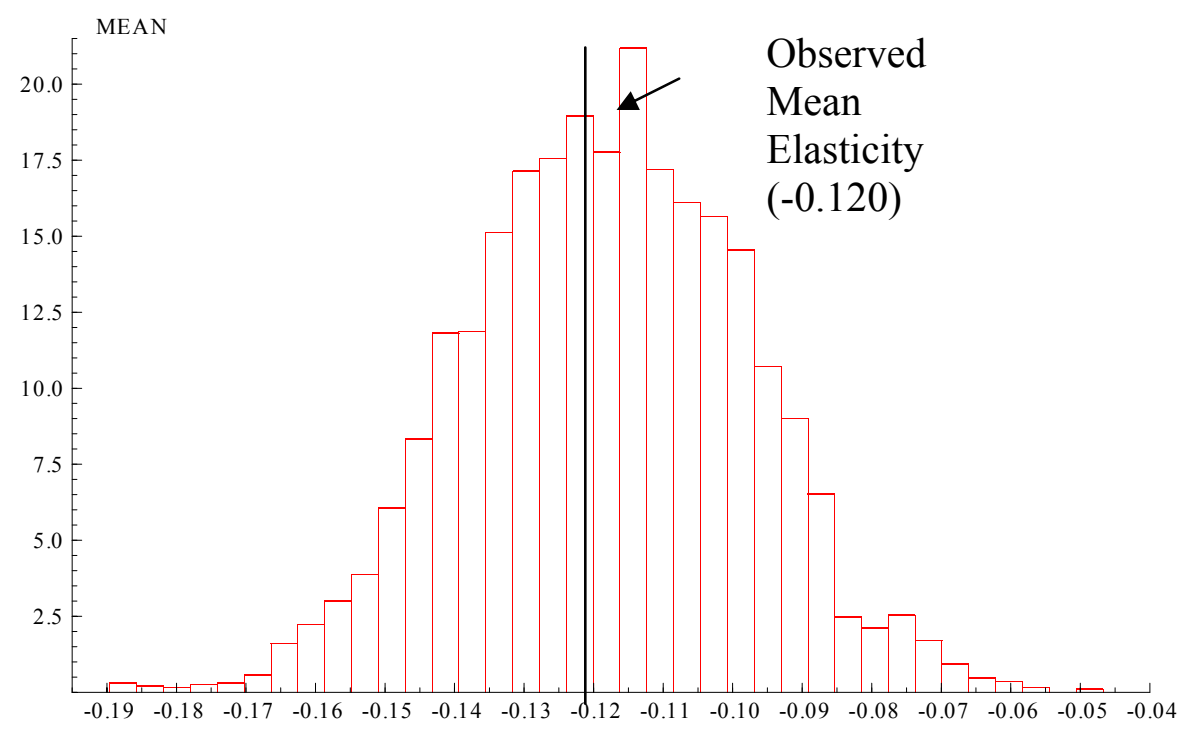


Fig 6: $\varepsilon_{S V B, Q B}$

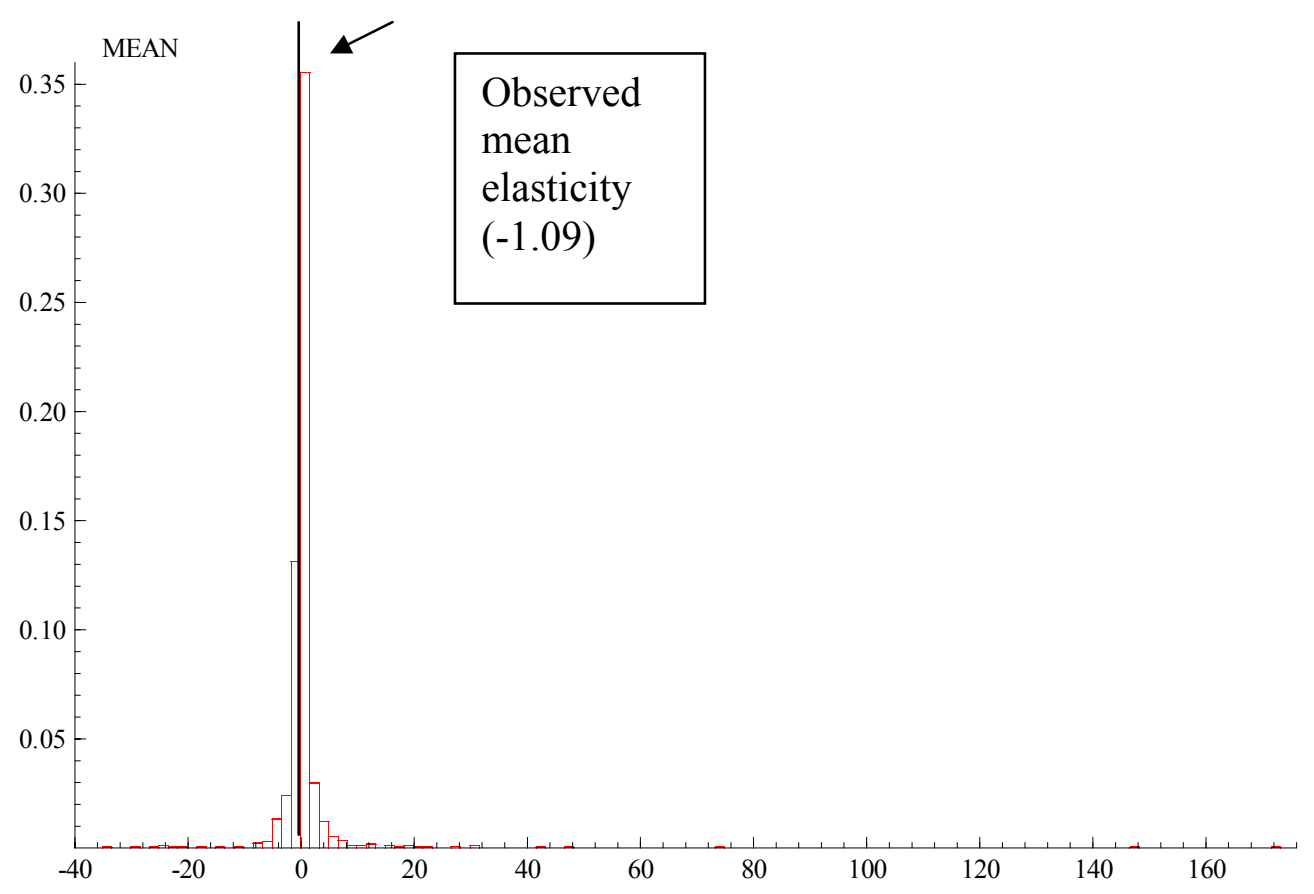




\section{Appendix Table A1}

English Counties included in study.

\begin{tabular}{|l|l|l|}
\hline Code & County & County Type \\
\hline AV & Avon & CTY \\
\hline CH & Cheshire & CTY \\
\hline CL & Cleveland & CTY \\
\hline CO & Cornwall & CTY \\
\hline CU & Cumbria & CTY \\
\hline DE & Devon & CTY \\
\hline DOR & Dorset & CTY \\
\hline DU & Durham & CTY \\
\hline GL & Gloucestershire & CTY \\
\hline HW & Hereford and Worcester & CTY \\
\hline HU & Humberside & CTY \\
\hline LA & Lancashire & CTY \\
\hline LE & Leicestershire & CTY \\
\hline LI & Lincolnshire & CTY \\
\hline NF & Norfolk & CTY \\
\hline NY & North Yorkshire & CTY \\
\hline NH & Northamptonshire & CTY \\
\hline NM & Northumberland & CTY \\
\hline NT & Nottinghamshire & CTY \\
\hline SL & Salop & CTY \\
\hline SO & Somerset & CTY \\
\hline ST & Staffordshire & CTY \\
\hline SF & Suffolk & CTY and Wear \\
\hline SU & Wiltshire & MET \\
\hline WI & Greater Manchester & MET \\
\hline GM & Serseyside & \\
\hline ME & & METh Yorksire \\
\hline SY & TY & \\
\hline
\end{tabular}




\begin{tabular}{|l|l|l|}
\hline WM & West Midlands & MET \\
\hline WY & West Yorkshire & MET \\
\hline BD & Bedfordshire & COM \\
\hline BK & Berkshire & COM \\
\hline BU & Buckinghamshire & COM \\
\hline CA & Cambridgeshire & COM \\
\hline ES & East Sussex & COM \\
\hline EX & Essex & COM \\
\hline HA & Hampshire & COM \\
\hline HE & Hertfordshire & COM \\
\hline OX & Oxfordshire & COM \\
\hline KE & Kent & COM \\
\hline WS & West Sussex & COM \\
\hline
\end{tabular}


Appendix Table A2: Parameter Estimates

\begin{tabular}{|c|c|c|c|c|}
\hline Parameter & Estimate & $\begin{array}{l}\text { Standard } \\
\text { Error }\end{array}$ & $\begin{array}{l}\text { t- } \\
\text { statistic }\end{array}$ & P-value \\
\hline$\alpha_{L L}$ & -378.33 & 151.22 & -2.50 & {$[.012]$} \\
\hline$\alpha_{\mathrm{KK}}$ & -1369.54 & 234.41 & -5.84 & {$[.000]$} \\
\hline$\alpha_{\mathrm{MM}}$ & -583.49 & 245.69 & -2.37 & {$[.018]$} \\
\hline$\alpha_{L K}$ & 156.82 & 29.85 & 5.25 & {$[.000]$} \\
\hline$\alpha_{\mathrm{LM}}$ & 425.45 & 107.74 & 3.95 & {$[.000]$} \\
\hline$\alpha_{\text {LM,MET }}$ & 592.91 & 493.14 & 1.20 & {$[.229]$} \\
\hline$\alpha_{\mathrm{LM}, \mathrm{COM}}$ & -346.86 & 157.40 & -2.20 & {$[.028]$} \\
\hline$\alpha_{\mathrm{KM}}$ & 450.02 & 110.10 & 4.09 & {$[.000]$} \\
\hline$\alpha_{\mathrm{KM}, \mathrm{COM}}$ & -347.27 & 147.74 & -2.35 & {$[.019]$} \\
\hline$\delta_{\mathrm{LG}}$ & 0.06 & 0.04 & 1.35 & {$[.176]$} \\
\hline$\delta_{\mathrm{KG}}$ & 0.21 & 0.04 & 4.83 & {$[.000]$} \\
\hline$\delta_{\mathrm{LG}, \mathrm{COM}}$ & -0.07 & 0.02 & -4.37 & {$[.000]$} \\
\hline$\delta_{\mathrm{MG}}$ & 0.70 & 0.04 & 15.58 & {$[.000]$} \\
\hline$\delta_{\mathrm{MG}, \mathrm{MET}}$ & -0.05 & 0.03 & -1.51 & {$[.132]$} \\
\hline$\delta_{\mathrm{LW}}$ & 0.00 & 0.39 & -0.01 & [.995] \\
\hline$\delta_{\mathrm{LW}, \mathrm{COM}}$ & -0.62 & 0.13 & -4.78 & {$[.000]$} \\
\hline$\delta_{\mathrm{KW}}$ & -0.21 & 0.40 & -0.52 & {$[.601]$} \\
\hline$\delta_{\mathrm{KW}, \mathrm{MET}}$ & 0.18 & 0.17 & 1.07 & {$[.286]$} \\
\hline$\delta_{\mathrm{MW}}$ & -0.96 & 0.41 & -2.37 & {$[.018]$} \\
\hline$\delta_{\mathrm{MW}, \mathrm{MET}}$ & 0.88 & 0.22 & 4.08 & {$[.000]$} \\
\hline$\delta_{\mathrm{Lt}}$ & 4.32 & 9.27 & 0.47 & {$[.641]$} \\
\hline$\delta_{\mathrm{Kt}}$ & 60.06 & 16.58 & 3.62 & {$[.000]$} \\
\hline$\delta_{\mathrm{Kt}, \mathrm{MET}}$ & -9.63 & 10.45 & -0.92 & {$[.357]$} \\
\hline$\delta_{\mathrm{Kt}, \mathrm{COM}}$ & -20.26 & 16.89 & -1.20 & {$[.230]$} \\
\hline$\delta_{\mathrm{Mt}}$ & -18.18 & 16.18 & -1.12 & {$[.261]$} \\
\hline$\delta_{\mathrm{Mt}, \mathrm{MET}}$ & 105.59 & 29.20 & 3.62 & {$[.000]$} \\
\hline$\delta_{\mathrm{Mt}, \mathrm{COM}}$ & 33.61 & 15.64 & 2.15 & {$[.032]$} \\
\hline$\delta_{\mathrm{L}, \mathrm{SIC}}$ & -7.56 & 5.99 & -1.26 & {$[.207]$} \\
\hline$\delta_{\mathrm{K}, \mathrm{SIC}}$ & 31.42 & 9.48 & 3.31 & {$[.001]$} \\
\hline$\delta_{\mathrm{M}, \mathrm{SIC}}$ & 50.75 & 11.31 & 4.49 & {$[.000]$} \\
\hline$\delta_{\mathrm{L}, \mathrm{AGE}}$ & 2.51 & 4.31 & 0.58 & {$[.560]$} \\
\hline$\delta_{\mathrm{K}, \mathrm{AGE}}$ & 20.74 & 7.20 & 2.88 & {$[.004]$} \\
\hline$\delta_{\mathrm{M}, \mathrm{AGE}}$ & -14.75 & 8.40 & -1.76 & {$[.079]$} \\
\hline$\delta_{\mathrm{L}, \mathrm{MET}}$ & -311.70 & 373.36 & -0.83 & {$[.404]$} \\
\hline$\delta_{\mathrm{M}, \mathrm{MET}}$ & -1108.28 & 706.97 & -1.57 & {$[.117]$} \\
\hline$\delta_{\mathrm{L}, \mathrm{COM}}$ & 325.91 & 119.67 & 2.72 & {$[.006]$} \\
\hline$\delta_{\mathrm{K}, \mathrm{COM}}$ & 507.00 & 250.90 & 2.02 & {$[.043]$} \\
\hline$\delta_{\mathrm{M}, \mathrm{COM}}$ & 457.72 & 231.94 & 1.97 & {$[.048]$} \\
\hline
\end{tabular}




\begin{tabular}{|l|r|r|r|l|} 
& 0.0000 & 0.0000 & -3.95 & {$[.000]$} \\
\hline$\gamma_{\mathrm{GG}}$ & 0.0000 & 0.0000 & -6.57 & {$[.000]$} \\
\hline$\gamma_{\mathrm{GW}, \mathrm{COM}}$ & 0.0001 & 0.0002 & 0.53 & {$[.597]$} \\
\hline$\gamma_{\mathrm{WW}, \mathrm{MET}}$ & -0.0008 & 0.0001 & -6.37 & {$[.000]$} \\
\hline$\gamma_{\mathrm{GW}}$ & 0.0002 & 0.0000 & 6.54 & {$[.000]$} \\
\hline$\gamma_{\mathrm{Gt}}$ & -0.0036 & 0.0038 & -0.95 & {$[.344]$} \\
\hline$\gamma_{\mathrm{Wt}}$ & -0.0094 & 0.0324 & -0.29 & {$[.771]$} \\
\hline$\gamma_{\mathrm{G}, \mathrm{SIC}}$ & 0.0030 & 0.0018 & 1.64 & {$[.101]$} \\
\hline$\gamma_{\mathrm{W}, \mathrm{SIC}}$ & -0.0565 & 0.0235 & -2.40 & {$[.016]$} \\
\hline$\gamma_{\mathrm{G}, \mathrm{AGE}}$ & 0.0020 & 0.0017 & 1.13 & {$[.260]$} \\
\hline$\gamma_{\mathrm{W}, \mathrm{AGE}}$ & -0.0039 & 0.0172 & -0.22 & {$[.823]$} \\
\hline$\gamma_{\mathrm{W}, \mathrm{COM}}$ & 0.4466 & 0.1495 & 2.99 & {$[.003]$} \\
\hline
\end{tabular}





\section{Research Paper Series \\ International Centre for Corporate Social Responsibility \\ ISSN 1479-5116}

\section{Editor: Dirk Matten}

The ICCSR Research Papers Series is intended as a first-hand outlet for research output of ICCSR. These include papers presented at symposiums and seminars, first drafts of papers intended for submission in journals and other reports on ongoing or completed research projects.

The objective of the ICCSR Research Papers Series is twofold: First, there is a time goal: Given the quality of ICCSR publication, the targeted journals normally require large time spans between submission and publication. Consequently, the ICCSR Research Papers Series serves as a preliminary airing to working papers of ICCSR staff and affiliates which are intended for subsequent publication. By this, research output can be made available for a selected public which will not only establish ICCSR's lead in advancing and developing innovative research in CSR but will also open the opportunity to expose ideas to debate and peer scrutiny prior to submission and/or subsequent publication. Second, the ICCSR Research Papers Series offers the opportunity of publishing more extensive works of research than the usual space constraints of journals would normally allow. In particular, these papers will include research reports, data analysis, literature reviews, work by postgraduate students etc. which could serve as a primary data resource for further publications. Publication in the ICCSR Research Paper Series does not preclude publication in refereed journals.

The ICCSR Research Papers Series consequently is interested in assuring high quality and broad visibility in the field. The quality aspect will be assured by establishing a process of peer review, which will normally include the Editor of the ICCSR Research Papers Series and one further academic in the field. In order to achieve a reasonable visibility the ICCSR Research Papers Series has full ISSN recognition and is listed in major library catalogues worldwide. All papers can also be downloaded at the ICCSR website.

\section{Published Papers}

No. 01-2003 Wendy Chapple \& Richard Harris

Accounting for solid waste generation in measures of regional productivity growth

No. 02-2003 Christine Coupland

Corporate identities on the web: An exercise in the construction and deployment of 'morality'

No. 03-2003 David L. Owen

Recent developments in European social and environmental reporting and auditing practice - A critical evaluation and tentative prognosis

No. 04-2003 Dirk Matten \& Andrew Crane

Corporate Citizenship: Towards an extended theoretical conceptualization

No. 05-2003 Karen Williams, Mike Geppert \& Dirk Matten

Challenges for the German model of employee relations in the era of globalization

No. 06-2003 lain A. Davies \& Andrew Crane

Ethical Decision Making in Fair Trade Companies

No. 07-2003 Robert J. Caruana

Morality in consumption: Towards a sociological perspective 
No. $08-2003$

No. $09-2003$

No. $10-2003$

No. $11-2003$

No. $12-2003$

No. $13-2003$

No. $14-2003$

No. $15-2003$

No. $16-2004$

No. $17-2004$

No. $18-2004$

No. $19-2004$

No. $20-2004$

No. $21-2004$
Edd de Coverly, Lisa O'Malley \& Maurice Patterson

Hidden mountain: The social avoidance of waste

Eleanor Chambers, Wendy Chapple, Jeremy Moon \& Michael Sullivan CSR in Asia: A seven country study of CSR website reporting

Anita Fernandez Young \& Robert Young

Corporate Social Responsibility: the effects of the Federal Corporate Sentencing Guidelines on a representative self-interested corporation

Simon Ashby, Swee Hoon Chuah \& Robert Hoffmann

Industry self-regulation: A game-theoretic typology of strategic voluntary compliance

David A. Waldman, Donald Siegel \& Mansour Javidan

Transformational leadership and CSR: A meso level approach

Jeremy Moon, Andrew Crane \& Dirk Matten

Can corporations be citizens? Corporate citizenship as a metaphor for business participation in society $\left(2^{\text {nd }}\right.$ Edition)

Anita Fernandez Young, Jeremy Moon \& Robert Young The UK Corporate Social Responsibility consultancy industry: a phenomenological approach

Andrew Crane

In the company of spies: The ethics of industrial espionage

Jan Jonker, Jacqueline Cramer \& Angela van der Heijden

Developing Meaning in Action: (Re)Constructing the Process of Embedding

Corporate Social Responsibility (CSR) in Companies

Wendy Chapple, Catherine J. Morrison Paul \& Richard Harris

Manufacturing and Corporate Environmental Responsibility: Cost Implications of Voluntary Waste Minimisation

Brendan O'Dwyer

Stakeholder Democracy: Challenges and Contributions from Accountancy

James A. Fitchett

Buyers be Wary: Marketing Stakeholder Values and the Consumer

Jeremy Moon

Government as a Driver of Corporate Social Responsibility: The UK in Comparative Perspective

Andrew Crane and Dirk Matten

Questioning the Domain of the Business Ethics Curriculum: Where the Law ends or Where it Starts? 